FRESCA, T.M. Londrina como centro de gestão do $t$ território: uma ...

\title{
Londrina como centro de gestão do território: uma discussão a partir de atividades privadas
}

Tânia Maria Fresca*

\section{Resumo}

$\mathrm{O}$ artigo discute o papel de Londrina (PR) como um centro de gestão do território a partir de atividades privadas, tratando-se de uma das dimensões da funcionalidade de uma cidade. Situada na $19^{\mathrm{a}}$ posição no número de empresas controladoras; $15^{\mathrm{a}} \mathrm{em}$ estabelecimentos filiais controlados; $31^{\text {a }}$ em estabelecimentos filiais atraídos; $28^{\mathrm{a}}$ em empresas atraídas; $30^{\mathrm{a}} \mathrm{em}$ número de assalariados externos na escala nacional pelo IBGE (2014) se questionou: quais atividades permitem a realização desta gestão? Quais são essas empresas? O que isso significa do ponto de vista de sua importância na escala nacional e regional? Em que escala espacial essa gestão é realizada? Utilizou-se o número de sede de empresas na cidade, as filiais externas e o número de assalariados externos como elementos para a realização do trabalho.

Palavras-chave: Gestão do território; Sede de empresas; Assalariados externos; Londrina (PR).

Londrina as center for the management of the territory: a discussion from private activities

\begin{abstract}
This article discusses the role of Londrina, in the state of Paraná, as an administrative center of the territory through private activities,

\footnotetext{
Professora da Universidade Estadual de Londrina - UEL (tania_geografia@yahoo.com.br).
}

Geosul, Florianópolis, v. 31, esPeCIAL, p 11-56, jul./dez. 2016 
FRESCA, T.M. Londrina como centro de gestão do $t$ território: uma ...

as one of the dimensions of a city's functionality. As the city comes in $19^{\text {th }}$ position for the number of parent companies; $15^{\text {th }}$ for establishments of controlled subsidiaries; $31^{\text {st }}$ for attracted branches; $28^{\text {th }}$ for attracted companies; and $30^{\text {th }}$ in the number of external employees at the national level, according to the IBGE (2014), the question arises: which activities allow this management to occur? Which are the companies? What does this mean from the perspective of its importance on the national and regional scale? In which spatial scale does this management take place? The number of company headquarters in the city, the number of controlled subsidiaries and the number of external employees were used as the elements to carry out this study.

Key words: Territorial management; Company headquarters; External employees; Londrina (PR).

\section{Introdução}

A cidade de Londrina configura-se como a segunda mais importante do estado do Paraná e a quarta da Região Sul do país em termos populacionais. O destaque do ponto de vista da geração de empregos tem sido os serviços e o comércio varejista, enquanto a indústria de transformação participa com aproximadamente 14\%. Colocava-se em 2013 como o 43 ${ }^{\mathrm{a}}$ maior em termos de PIB (IBGE, 2015) no país, do qual a maior parcela estava no setor terciário.

Ao mesmo tempo, sua condição de principal cidade de uma aglomeração urbana com mais de um milhão de habitantes (IBGE, 2015), lhe confere posição de evidência diante de suas atividades urbanas, porque as mesmas atendem demandas das famílias e empresas das cidades da aglomeração, denotando fortes relações de integração e interdependência. A partir dos dados do IBGE (2014, p. 75) foi possível identificá-la como uma das mais importantes em termos de gestão do território, ocupando: $19^{a}$ posição em empresas controladoras; $15^{\mathrm{a}}$ em estabelecimentos filiais controlados; $31^{\mathrm{a}} \mathrm{em}$ 
FRESCA, T.M. Londrina como centro de gestão do $t$ território: uma ...

estabelecimentos filiais atraídos; $28^{\mathrm{a}}$ em empresas atraídas; e $30^{\mathrm{a}}$ em número de assalariados externos. Trata-se de posições em relação às atividades privadas. Do ponto de vista da gestão pública, sua posição é bem menor, tendo em vista que os órgãos públicos têm suas sedes em Brasília (federal), a partir da qual ocorre uma distribuição dos órgãos em estrutura hierárquica.

Destes elementos emergiram alguns questionamentos: quais atividades permitem a realização desta gestão? Quais são essas empresas? O que isso significa do ponto de vista de sua importância na escala nacional, regional e local? Em que escala espacial essa gestão é realizada?

Diante do exposto, o objetivo do presente trabalho é identificar o papel de Londrina - PR, enquanto um centro de gestão do território a partir de atividades privadas, tratando-se de uma das dimensões da funcionalidade de uma cidade. Para que o mesmo seja alcançado, destacam-se os seguintes objetivos específicos: levantar quais empresas privadas que apresentam suas sedes em Londrina e filiais no Brasil e no exterior; caracterizar estas empresas do ponto de vista de suas atividades, de sua área de atuação, do número de assalariados externos, das relações de decisão e comando das atividades a partir da sede e/ou as assimetrias do ponto de vista das decisões; e correlacionar esta discussão com o processo de metropolização.

A gestão do território é aqui entendida como "[...] as ações exercidas pelos agentes sociais, privados e públicos, no sentido de apropriar-se de um território" (CORRÊAA, 1989, p. 17), cujas ações visam garantir a reprodução do sistema capitalista. Estabelecem práticas espaciais diversas, visando criação e controle de uma dada organização espacial, bem como o controle de processos que geram transformações espaciais, das quais o autor destaca a concentração e dispersão (CORRÊA, 1995). Trata - se, portanto, de uma faceta da gestão econômica, política e social.

Um centro de gestão do território configura-se em uma cidade onde se localizam empresas ou órgãos públicos e empresas 
FRESCA, T.M. Londrina como centro de gestão do t território: uma ...

privadas de diferentes ramos de atividades, cujas decisões sobre investimentos, produção, mercado consumidor, inovações, etc., afeta direta ou indiretamente um dado espaço, região, rede urbana que fica sob o controle e influência da cidade pelas empresas nela sediada (CORRÊA, 1995).

A gestão por grandes cidades, não exclusivamente, é tema relevante, na medida em que põe em destaque a capacidade de direção e decisão de atividades regionais. Decisões exercidas por agentes privados ou públicos "[...] no sentido de apropriar-se de um território e controlar a sua organização socioespacial" (CORRÊA, 1989, p. 17), visando garantir condições para a acumulação capitalista e reprodução diferenciada das classes sociais. Mais que isso, porque esta temática põe em relevo a presença de grupos econômicos regionais, que se contrapõem às grandes corporações, haja vista a possibilidade de sua forte atuação regional, à perspectiva de instaurarem especializações produtivas e ao mesmo tempo, disputarem mercados nacionais. Inclui-se ainda o fato de determinadas cidades comandarem parcela de atividades diversas, inclusive a financeira mediante sistema cooperativo de crédito.

Corrêa (1989) aponta duas abordagens para o estudo da gestão do território: a primeira baseada no número de sedes sociais que concentram o capital fixo controlado e os setores de atividades; e a segunda, que considera a dimensão espacial, através da localização de filiais e número de assalariados externos. Este último dado indica "[...] o controle que um dado centro exerce sobre a vida econômica, política e social de um determinado lugar, afetando o nível de empregos diretos e indiretos, a renda e os impostos" (CORRÊA, 1995, p. 84). Acrescenta o autor que, o uso de número de assalariados externos possibilita, quando acompanhado dos detalhamentos das atividades em que os assalariados externos estão atuando, a compreensão da inserção de um centro na divisão territorial do trabalho da empresa, do país e 
FRESCA, T.M. Londrina como centro de gestão do $t$ território: uma ...

regionalmente (CORRÊA, 1995). Adota-se neste trabalho a dimensão espacial.

Como se trata de uma pesquisa que não tem similar na bibliografia, inicialmente o trabalho apoia-se em um percurso exploratório, mas incorpora uma abordagem analítica. Uma pesquisa como esta, se caracteriza por ser uma primeira aproximação sobre o tema da pesquisa, obter critérios para abordagem da questão, estabelecer prioridades de pesquisas, gerar um novo tipo de enfoque sobre o tema, dentre outros, considerada por Gil (1995) como método exploratório. A discussão sobre a gestão do território por um centro urbano tem sido realizada prioritariamente a partir de estudos que envolvem o uso de diversos dados (número de sede de empresas, de filiais, capital controlado, etc.) para cidades na escala nacional como tem sido os estudos do IBGE (2014). Têm-se ainda estudos sobre empresas públicas ou privadas que apresentam grande destaque como estudos de Brito (2008), Pires do Rio (2000), Toledo e Kahil (2004), a partir dos quais se podem verificar diversos aspectos da gestão do território. O desvendamento de quais são as empresas sediadas em uma cidade, as atividades, localização de filiais e assalariados externos não tem sido o enfoque dos estudos geográficos. Advém deste fato a pesquisa exploratória, mas acrescida de uma abordagem analítica em direção à compreensão de aspectos dessa temática em Londrina.

Do ponto de vista operacional, baseou-se em fontes primárias e secundárias. Estas últimas tiveram como ponto de partida os dados informados pelo IBGE (2014), sobre relações entre sedes e filiais de companhias privadas e referem-se ao ano de 2011. No entanto, como a escala do citado trabalho é nacional, são apresentados apenas os números de sede de empresas e assalariados externos no que se refere à gestão privada para cada cidade, não sendo possível identificar as empresas, as atividades e a localização das filiais. 
FRESCA, T.M. Londrina como centro de gestão do $t$ território: uma ...

Tendo as informações do estudo do IBGE (2014) como ponto de partida, procedeu-se aos levantamentos primários, tarefa concretizada inicialmente através de levantamento de informações sobre as principais empresas privadas da cidade de Londrina com filiais externas em sindicatos, associações, organizações, dentre outras $^{1}$. A partir da obtenção de listagem de empresas, procedeu-se à pesquisa no sítio das mesmas, visando obter informações históricas e dados disponíveis. A próxima etapa configura-se em entrevistas e diálogos informais nas empresas para obtenção de informações sobre a localização de filiais externas, número de assalariados externos, bem como aspectos do processo de gestão da empresa. Vale observar que, informações a respeito da gestão empresarial, fornecem importantes subsídios para identificação de mecanismos através dos quais se realiza a gestão do território. Dada a amplitude do trabalho mediante quantidade das empresas privadas, não foi possível discutir aqui as práticas espaciais. $\mathrm{O}$ conjunto de informações permitiu a caracterização de empresas quanto a seus ramos de atividades, localização de suas filiais, número de assalariados externos. As informações não atingem a totalidade de empresas sediadas na cidade e que apresentam filiais externas até outubro de 2015.

1 Os levantamentos foram realizados no Instituto de Desenvolvimento de Londrina - Codel; Federação das Indústrias do Estado do Paraná, escritório de Londrina; de Londrina e Região; Associação Comercial e Industrial de Londrina; Sindicato do Comércio Varejista; Sindicato dos Trabalhadores na Indústria de Alimentação; Sindicato das Indústrias Metalúrgicas de Londrina e Região; Sindicato das Indústrias do Vestuário de Londrina e Região; Sindicato das Indústrias Químicas e Farmacêuticas de Londrina; Sindicato das Indústrias da Construção Civil do Norte do Paraná; Clube de Engenharia e Arquitetura de Londrina; Escritório Regional em Londrina da Associação Paranaense de Supermercados; Sindicato dos Trabalhadores em Transporte Rodoviário de Londrina. 
FRESCA, T.M. Londrina como centro de gestão do $t$ território: uma ...

\section{Estruturas empresariais e articulações espaciais com a gestão do território}

A gestão do território para controlar vasta parcela da economia, tem sido realizada principalmente pelas metrópoles, tendo em vista que, na sua constituição ao longo do tempo, tornouse local privilegiado para a concentração de atividades produtivas, comerciais e de serviços que lhe foi garantindo, por diversos mecanismos, poder de decisão e gestão. Em outras palavras, criavam-se as economias de aglomeração urbanas no capitalismo a partir do século XVIII.

Isto se vincula às mudanças de estratégias e estruturas de grandes empresas apontadas por Chandler (apud MCGRAW, 1998) para o contexto norte-americano desde o século XIX. O autor apontava que, no processo histórico de formação e evolução de grandes empresas, diversas estratégias foram adotadas como fusões e aquisições, criação de outros modelos de organização interna e concorrência externa, criação de departamento de pesquisa e desenvolvimento de produtos, outras formas de comercialização, estrutura verticalizada, burocratização, controle da informação, etc., que colocavam a decisão e controle da economia em metrópoles como Chicago, N. York, Boston, Filadélfia, dentre outras. Estas concentravam naquele momento, as melhores condições para a reprodução do capital: mão de obra, serviços direcionados às empresas, transporte, acesso a mercado consumidor, dentre outros.

Mas já deixava claro que, a criação de novos mercados demanda, renda do consumidor, inovações tecnológicas - e o aumento da produção, tornavam a estrutura centralizada da grande empresa ineficiente. A solução encontrada foi a criação de uma estrutura descentralizada, onde havia certo controle da matriz ou escritório central, com várias subdivisões que podiam funcionar quase autonomamente. Emergia assim, a separação espacial entre 
FRESCA, T.M. Londrina como centro de gestão do $t$ território: uma ...

direção, produção e comercialização, bem como unidades especializadas apenas em funções administrativas.

Neste tipo de organização, o escritório geral planeja, coordena e avalia o trabalho de várias divisões operacionais e distribui entre elas o pessoal, o equipamento, as verbas e outros recursos necessários. Os executivos encarregados dessas divisões, por sua vez, têm sob seu comando a maioria das funções necessárias para lidar com uma linha de produtos ou um conjunto de serviços numa ampla área geográfica, sendo cada qual responsável pelos resultados financeiros de sua divisão e pelo sucesso no mercado (CHANDLER apud MCCRAW, 1998, p.122).

$\mathrm{Na}$ medida em que se expandia a grande empresa, principalmente aquelas com várias unidades dispersas em um país, Pred (1979) apontava o fato de que, após a II Guerra Mundial, ocorreram vários processos em direção à continuidade de fusões e aquisições, expansão física da produção e unidades, aumento dos serviços administrativos e informações relacionadas à tomada de decisões, controle e coordenação, avanço tecnológico para transportes, comunicações, produção propriamente dita, dentre outros, que em parte, alteraram as estruturas espaciais hierárquicas das grandes empresas.

Pred (1979) argumentava que, a partir dos anos de 1960, ocorreu outra etapa para a formação e expansão das corporações altamente diversificadas, mediante continuidade de fusões e aquisições com concentrações horizontais e verticais. Do ponto de vista da estrutura espacial, continuaram com tendência hierárquica assimétrica, com especializações de atividades entre os centros urbanos, principalmente os metropolitanos.

Quanto às articulações entre as corporações e as cidades, o autor evidenciou três tipos de inter-relações. A primeira diz respeito aos efeitos multiplicadores diretos (inter e intraorganizacionais) e indiretos que, ocorrem na escala local, 
FRESCA, T.M. Londrina como centro de gestão do $t$ território: uma ...

escala essa derivada do aumento da demanda e consumo pessoal, criado pela expansão da corporação e seus multiplicadores intra e interorganizacionais. A segunda são as inovações criadoras de empregos, cuja difusão se realizava visando ampliar os tipos de produtos e serviços para demanda final ou intermediária, o uso de novos processos de produção e organizacionais, que incorporam novas relações estruturais no interior da corporação, novos procedimentos de planejamento, etc. (PRED, 1979). A terceira são as decisões, especialmente aquelas de natureza operacional envolvendo: decisões de compra (insumos, serviços de transporte, publicidade, etc.), decisões de mercado, decisões de investimentos e decisões públicas de investimentos. É importante notar que, cada uma destas, tem dimensão espacial, afetando uma cidade ou conjunto das mesmas, bem como a circulação da informação no sistema urbano, que são processadas pela sede social da corporação.

Estes elementos evidenciam que, ocorreu e ainda ocorre um processo de descentralização da função de poder e decisão. Do ponto de vista da decisão e controle, há hierarquias: a sede social da empresa, responsável pelo controle e planejamento estratégico, cuja localização tende a ser metropolitana; o escritório das divisões regionais, cujas localizações podem ser diversas dependendo do tipo de empresas e produções e as unidades sub-regionais ou locais de nível inferior da hierarquia, que podem ser desde pequenas cidades até cidades metropolitanas de importância regional ou nacional (PRED, 1979).

Neste sentido, há importantes articulações entre as formas através das quais grandes empresas e corporações estão estruturadas espacialmente e a gestão do território. Estas corporações constituem poderosas redes empresariais em distintos países, cujas cidades onde se fazem presentes, estão fortemente integradas em redes econômicas internacionais (ROZEMBLAT, 1996). Se por um lado, no contexto europeu a autora demonstra continuidade do poder das principais metrópoles enquanto sedes 
FRESCA, T.M. Londrina como centro de gestão do $t$ território: uma ...

sociais de empresas multinacionais, por outro, também evidencia a presença das mesmas em cidades de outros escalões vinculadas à suas produções específicas.

No contexto do capitalismo contemporâneo, marcado dentre outros, pelos oligopólios de mercados, globalização, neoliberalismo, financeirização, etc., Chesnais (1996) aponta o fato de que, as sedes sociais de multinacionais como grupo, configuram-se como centros de decisões financeiras, com “[...] permanente arbitragem das participações financeiras que detém, em função da rentabilidade dos capitais envolvidos" (CHESNAIS, 1996, p. 75-76). De outro lado, suas filiais e/ou subsidiárias exploram algumas atividades, formando o que o autor denominou de empresas-rede. Segundo o autor, isto foi possível mediante o avanço das tecnologias de informação. Chesnais (1996) aponta ainda que essas tecnologias permitiram que cada filial ou subsidiária de uma corporação, pudesse controlar em termos de preços sua produção em mercados internos, defender seus interesses diante de outras empresas do grupo para obter investimentos e mesmo transferir recursos para novos investimentos.

Ao mesmo tempo, explicitava que o uso da microeletrônica, possibilitou proliferação de especializações entre empresas/subsidiárias/filiais de grandes corporações com aprofundamento da divisão do trabalho. O autor entende que "[...] certa desintegração técnica permite um controle mais apertado dos custos e da qualidade" a partir da sede da corporação. Isto porque "[...] a gestão computadorizada dos fluxos externos, isto é, entre as companhias, bem como a maior precisão da fabricação, permitem às companhias principais coordenar seus terceirizados" (CHESNAIS, 1996, p. 108).

Em outros termos, as corporações no final do século XX, passaram a subdividir cada vez mais o processo de gestão e controle das suas atividades, sejam produtivas ou de serviços, mediante rede de empresas especializadas. Por isso: 
FRESCA, T.M. Londrina como centro de gestão do t território: uma ...

[...] a empresa-rede apresenta-se então, não como uma 'ruptura' com as hierarquias e a internalização, mas antes como uma nova forma de organizar e de gerenciar essas hierarquias, bem como de maximizar as possibilidades de 'internalizar' as 'externalidades'(CHESNAIS, 1996, p. 109).

Aqui se tem elementos importantes em direção a entender a formação de unidades de negócios das corporações, enquanto estratégia para a descentralização administrativa a funcionarem quase autonomamente, delineando seu próprio plano de negócios, mas articuladas à sede social mundial ou na escala de um país (MINTZBERG et. al., 2007; OLIVEIRA, ÁVILA, 1998). Nesse sentido, essas unidades de negócios passaram a ter parcela (dependente da estrutura empresarial da corporação) de poder de decisão sobre suas estratégias de investimentos, de mercado consumidor, processos de produção, aumento da área de venda, empregos, etc.

Corrêa (1991) aponta como características relevantes das corporações vinculadas às implicações espaciais: sua ampla escala de operações (produção, serviços, pesquisa, etc.); a natureza multifuncional pela concentração vertical; a segmentação da corporação com diferenças entre unidades; as múltiplas localizações em um país, desde metrópoles até cidades de diferentes tamanhos; articulado aos interesses da mesma evidenciase uma divisão territorial do trabalho; e o poder de pressão econômica e política que a corporação exerce em diferentes regiões e países. Por isso, afirma que as corporações tornaram-se o mais importante agente da reorganização espacial capitalista após a Segunda Guerra Mundial (CORRÊA, 1991).

Em outros termos, especialmente após os anos de 1970, ocorreram profundas transformações no que respeita a organização das empresas e corporações, vinculada à denominada reestruturação produtiva. Esta última engloba uma série de significados, que nem sempre vêm acompanhados de explicações 
FRESCA, T.M. Londrina como centro de gestão do t território: uma ...

efetivas ao serem utilizados. Isto porque, segundo Pires do Rio (1998), a expressão pode vincular-se a micro decisões de eficiência técnico-produtiva; diferentes formas de flexibilização da produção; diversidade de estratégias de sistemas produtivos; diferentes contextos locais e regionais para investimentos, através de aquisições ou fusões; novas regulamentações, dentre outros. Tanto é assim que, esta expressão também utilizada nas discussões de geografia urbana, aparece como parte da explicação do processo de descentralização das atividades urbanas; para explicar a contínua mobilidade das áreas de investimentos de grandes construtoras e incorporadoras; como expressão que designa mudanças nas atividades comerciais e prestadoras de serviços, dentre outras.

De acordo com a autora "[...] essa noção transcende, portanto, as práticas utilizadas pelas grandes corporações, sem, no entanto, excluí-las como atores desse processo" (PIRES DO RIO, 1998, p. 54). Por isso entende a autora que, a reestruturação produtiva é um processo diferenciado no tempo e no espaço, conferindo aos lugares, um caráter mundial, vinculado às intermediações de articulações horizontais e verticais.

No entanto, é necessário ressaltar que o processo de reestruturação conforme explicitado acima, está em constante movimento, vinculado às estratégias de agentes sociais na busca de atividades, de processos e produtos que maximizem seus ganhos, e por conta disso, acabam criando formas e funções, advindas de processos oriundos do movimento geral, da estrutura (SANTOS, 1985). Essa última referindo-se à própria formação econômica social e espacial (SANTOS, 1982), compreendida como uma estrutura técnico-produtiva, expressa geograficamente por certa distribuição da atividade de produção, correlacionada à produção propriamente dita, distribuição, circulação e consumo. A evolução da estrutura ou formação social está articulada tanto a fatores internos como externos, evidenciando ora a força de um, ou outro ou ainda a combinação de ambos em direção a uma complexidade mais acentuada. Desta maneira, as reestruturações produtivas 
FRESCA, T.M. Londrina como centro de gestão do t território: uma ...

ocorrem onde condições de instalação se apresentem melhores, sejam elas articuladas aos movimentos mais globais ou a própria formação enquanto uma potencialidade para a realização das reestruturações.

Nesse sentido, a totalidade da mutação cria uma nova organização espacial, sendo necessário entender tal organização enquanto manifestação da totalidade (SANTOS, 1985). Em outros termos " [...] quando a sociedade muda, o conjunto de suas funções muda em quantidade e qualidade. Tais funções se realizam onde condições de instalação se apresentem melhores" (SANTOS, 1996, p. 93).

Assim, parcela das mudanças na estrutura das empresas pode ser correlacionada à expansão do toyotismo (CORIAT, 1994), especialmente após as crises do petróleo nos anos de 1970, e que entre várias implicações, impuseram às corporações busca de outras estruturas empresariais para enfrentamento da crise. No entanto, é preciso considerar que, se em algumas empresas a implantação do toyotismo na produção de mercadorias e na administração foi mais rápida, em outras ocorreu mais tardia e em outras permaneceu fordista. Isso está relacionado ao enfrentamento de condições históricas japonesas, a importante atuação dos sindicatos e especificidades da produção.

Nesse percurso, muitas corporações caminharam em direção a uma gestão toyotista, isto é, princípios colocados por esse sistema de inovações organizacionais da produção de mercadorias, foram transpostos também para a estrutura administrativa. Exemplar deste processo são as atividades terceirizadas de limpeza, alimentação, segurança, manutenção de máquinas e equipamentos, etc.

Entretanto, a gestão do território por uma cidade não se realiza apenas por corporações e grandes empresas. Outras de porte médio e até pequeno participam desse processo, envolvendo capacitações por parte dos empresários para expansão de diferentes atividades, do mercado consumidor, dentre outros. É evidente que estas não conseguem competir com as corporações, mas acabam 
FRESCA, T.M. Londrina como centro de gestão do $t$ território: uma ...

atuando em nichos de mercados que grandes empresas não atuam. É o caso de pequenos supermercados, lojas de móveis, calçados, etc., localizados em pequenas cidades. Estas se tornaram locais preferenciais para implantação de filiais de atividades citadas, para mercado consumidor que necessita satisfazer suas demandas de produtos básicos e para os quais a proximidade é fundamental.

Diante destes elementos, é necessário retomar articulações entre as mudanças nas corporações e a gestão do território a partir das cidades onde estão situadas ${ }^{2}$. A partir de estudos de Corrêa (1989, 1991a, 1991b, 1992, 1995), é possível entender como a gestão administrativa de empresas e/ou corporações e de integração territorial da produção, contribuem para processos de gestão do território. Particular atenção deve ser dada às interações espaciais, que segundo Pires do Rio (1998), interrompem com interpretações da corporação e suas unidades como se fosse apenas uma localização. Isto porque demonstra como as decisões estruturantes das corporações podem afetar a posição de uma cidade na rede urbana. Isso implica que, as interações espaciais enquanto "[...] um amplo e complexo conjunto de deslocamentos de pessoas, mercadorias, capital e informação sobre o espaço geográfico" (CORRÊA, 1997, p. 279), se realizam com variações em termos de intensidade, frequência, distância e direção, objetivos e por diversos meios e velocidade. Mais ainda, porque as mesmas devem ser entendidas como parte integrante da existência (e reprodução) e do processo de transformação desigual.

Por intermédio das interações espaciais é possível entender os complexos fluxos materiais e imateriais que se realizam a partir de uma corporação, e entender dinâmicas da gestão do território enquanto fenômeno social, a partir de um centro urbano. Assim, a gestão do território por uma cidade vincula-se à presença de

2 Algumas referências sobre articulações da gestão com corporações e grandes empresas na escala internacional, podem ser verificadas em: Dunning, Lundan (2008), Cantwell (2014), Rozemblat ( 1996), dentre outros. 
FRESCA, T.M. Londrina como centro de gestão do $t$ território: uma ...

empresas de diferentes atividades, que podem ser estatais, privadas nacionais ou internacionais; de diferentes tamanhos em termos de empregados e capital; com distintas formas administrativas empresariais, desde as mais hierarquizadas até aquelas em que as unidades de negócios têm parcela do controle das decisões; de diferentes lógicas da distribuição de suas unidades produtivas industriais em uma região, afetando diretamente os diversos escalões de centros de uma rede urbana, dentre outros, presentes em uma cidade.

A presença destas empresas e corporações em uma cidade vincula-se à seletividade espacial, entendida como a escolha de um centro para a sua implantação, por diversos fatores (CORRÊA, 1992) como: formas de aquisição e produção de matérias primas, podendo gerar especialização produtiva ou uma marginalização; formas de distribuição da matéria prima entre unidades de negócios ou filiais, vinculadas ao sistema de transporte; do controle da contratação de trabalhadores com diferentes níveis de qualificação e especialização de distintos lugares afetando o mercado de trabalho; da forma como são elaboradas informações a serem distribuídas para distintas unidades produtivas em um país ou continente, implicando em controle ideológico; de diferentes formas de integração produtiva entre as filiais ou subsidiárias de uma empresa ou corporação, que não são hierárquicas; integração administrativa; mobilização de mais valia, dentre outras.

A partir de suas atuações, Corrêa (1991a) chama a atenção para as implicações espaciais das ações das corporações e empresas, sendo a primeira delas o contínuo processo de manter, desfazer e recriar diferenças espaciais, e a segunda como "[...] a perda do poder de controle e decisão das cidades da hinterlândia dos centros de gestão" (CORRÊA, 1991a, p. 114), na medida em que a implantação de grandes empresas ou corporações com atividades comerciais e industriais implica perda para a cidade e até mesmo para aquelas adjacentemente localizadas, na medida em que não possuem poder de competição. 
FRESCA, T.M. Londrina como centro de gestão do $t$ território: uma ...

Neste percurso não se pode esquecer as normas, que segundo Santos (1996) tornaram-se um dos fundamentos do desempenho e rentabilidade das empresas e são estruturadoras da realidade. Estas podem ser internas e relativas ao seu funcionamento técnico - afetando o entorno da empresa mediante horário de funcionamento, impostos, custos, preços, empregos, etc. -, como externas "[...] relativas ao seu comportamento político, nas suas relações com o poder público e nas suas relações regulares ou não, com outras firmas, sejam relações de cooperação ou de concorrência" (SANTOS, 1996, p. 183).

Mediante normas em diversos aspectos, a regulação da economia e do território impõe-se com mais força mediante a fragmentação da produção e sua dispersão geográfica, mas reunificada por diversos mecanismos de controle. Para Santos (1996, p. 185) "As novas necessidades de complementaridade surgem paralelamente à necessidade de vigiá-las, acompanhá-las e regulá-las". Nesta perspectiva, acrescenta o autor que "Estas novas necessidades de regulação e controle estrito mesmo à distância constituem uma diferença entre complementaridades do passado e as atuais" (SANTOS, 1996, p. 185), articuladas ao aprofundamento da divisão do trabalho. $\mathrm{O}$ exposto até o presente possibilita um dos caminhos para entender o crescimento de uma cidade do ponto de vista de suas atividades econômicas e a área de atuação das mesmas.

\section{Os principais centros de gestão do território brasileiro na segunda década do século XXI}

Alguns estudos já foram realizados para a compreensão da temática no Brasil, com destaque para Magnanini e Lima (1971), Cordeiro (1987), Corrêa (1968, 1989, 1991a, 1991b, 1995), dentre outros. O trabalho de Magnanini e Lima (1971) baseado no número de sedes de empresas industriais, comerciais e de serviços e em seus capitais por elas controladas, demonstrou a existência de 31 
FRESCA, T.M. Londrina como centro de gestão do $t$ território: uma ...

cidades principais na função de controle e decisão no final dos anos de 1960. Corrêa (1968) quando discutiu o papel dirigente das metrópoles brasileiras baseado nos dados sobre atividade industrial, através do número de sedes e assalariados externos, deparou-se com nove metrópoles (anterior ao processo de institucionalização das primeiras regiões metropolitanas brasileiras), estando no topo a cidade de São Paulo, seguida por Rio de Janeiro sendo consideradas como nacionais e Belo Horizonte, Porto Alegre, Curitiba, Recife, Salvador, Fortaleza e Belém como regionais. Ratificava ainda que, a maior importância em seu papel dirigente estava com as metrópoles do Centro Sul do país.

Cordeiro (1987) ao discutir os principais pontos de controle da economia transacional no Brasil, evidenciou a continuidade da concentração desta atividade nas nove primeiras regiões metropolitanas e Brasília, com posição dominante de São Paulo e Rio de Janeiro; o Centro Sul do país tinha os principais centros do controle da economia transacional; porém a autora verificou a expansão de um padrão assimétrico, onde regionalmente era diversa, evidenciando desde aquelas mais ricas e elaboradas como o Sudeste e o Sul, a mais equilibrada e onde cidades de escalões não metropolitanos respondiam por serem sedes de empresas. Esta concentração da atividade bancária também foi encontrada por Corrêa (1989) ao discutir as redes bancárias no Brasil.

O estudo do IBGE (2014) realizado para a escala nacional sobre a gestão do território com enfoque no tema redes e fluxos, traz vários elementos que evidenciam o conjunto das principais cidades brasileiras com papel na função de decisão e poder público e privado. Do ponto de vista da gestão privada, foram levantadas informações sobre o número de sede de empresas nas cidades, filais externas à mesma, trabalhadores assalariados externos à sede empresarial, bem como "[...] o poder de atração do município em reter filiais de empresas sediadas fora do mesmo", permitindo obter informações sobre controle e atração e "[...] interações com outras 
FRESCA, T.M. Londrina como centro de gestão do $t$ território: uma ...

unidades territoriais localizadas em todo o Brasil" (IBGE, 2014, p. 20).

A partir de seus resultados e articulado aos objetivos do presente trabalho, elaborou-se o quadro 1 com os 50 centros urbanos mais importantes do Brasil do ponto de vista da gestão, baseado no número de assalariados externos. O quadro permite verificar que: a) o maior número de centros está concentrado no estado de São Paulo, com 15 cidades, representando 30\% deste total; a cidade de São Paulo tem o maior poder do ponto de vista da gestão territorial, apresentando o maior número de todos os elementos presentes no quadro, ratificando a posição da metrópole no contexto nacional; além dela, mais 06 cidades estão em sua região metropolitana; b) Santa Catarina coloca-se como o segundo estado com maior número de cidades; c) Empatados na terceira, quarta e quinta posições com 04 cidades cada, estão Minas Gerais, Paraná e Rio de Janeiro; d) com duas cidades cada, estão o Rio Grande do Sul, Pernambuco e Goiás; com apenas 01 cidade aparecem os estados nordestinos, mais o Espírito Santo e Brasília; e) em termos regionais, o Sudeste representou $48 \%$ do total; o Sul com $24 \%$, Nordeste com 18\%, Centro Oeste com 6\% e Norte com $4 \%$.

Chama a atenção o número de cidades que não são metrópoles na condição de exercício de parcela do poder e controle sobre atividades privadas. Dentre os 50 maiores, 25 não são considerados metrópoles e não estão inseridos nas 12 principais regiões metropolitanas do país (São Paulo, Rio de Janeiro, Curitiba, Porto Alegre, Belo Horizonte, Salvador, Recife, Fortaleza, Belém, Brasília, Manaus e Goiânia). Dos 25 municípios, 6 eram capitais estaduais (Maceió, Vitória, São Luís, Teresina, Natal e Florianópolis); os demais eram municípios de diversos estados e São Paulo, no qual se inclui Campinas, Jaguariúna, Jundiaí, dentre outros, inseridos na denominada macro - metrópole paulista. Em Santa Catarina além de sua capital como um dos centros de gestão do território, contava com mais 05 municípios 
FRESCA, T.M. Londrina como centro de gestão do t território: uma ...

dentre os principais: Itajaí, Concórdia, Joinville, Chapecó e Blumenau. O mesmo se verifica com o Paraná, que além de Curitiba, contava com mais 03: Londrina, Maringá e Cascavel. 
FRESCA, T.M. Londrina como centro de gestão do $t$ território: uma ...

Quadro 1: Os 50 principais centros de gestão do território brasileiro a partir do número de assalariados externos, 2011

\begin{tabular}{|c|c|c|c|c|c|c|c|}
\hline Município & $\begin{array}{c}\text { Pop. Total res. } \\
2010\end{array}$ & \begin{tabular}{|c|} 
Assalariados \\
extemos \\
comandados \\
pelo municipio \\
\end{tabular} & $\begin{array}{c}\text { Emp. } \\
\text { Contro-ladoras }\end{array}$ & $\begin{array}{c}\text { Estab-filiais } \\
\text { controlados }\end{array}$ & $\begin{array}{c}\text { Estab. } \\
\text { filiais atraidos }\end{array}$ & $\begin{array}{l}\% \text { de assal ariado: } \\
\text { das emprasa sad } \\
\text { fora dos limites } \\
\text { mun sobre total }\end{array}$ & $\begin{array}{c}\text { Diversidade na } \\
\text { oferta serviços } \\
\text { apoio as } \\
\text { entpresas } \% \\
\end{array}$ \\
\hline S. Psulo & \begin{tabular}{|l|}
11253503 \\
\end{tabular} & \begin{tabular}{|l|}
1442425 \\
\end{tabular} & 9371 & 41291 & 12252 & \begin{tabular}{|l|}
11,15 \\
\end{tabular} & 97,78 \\
\hline R.J. & 6320446 & 580019 & 3179 & 11823 & 8191 & 17,63 & 97,78 \\
\hline Brasilia & 2570160 & 390775 & 868 & 18014 & 3006 & 14,68 & 88,89 \\
\hline B. H. & 2375151 & 211529 & 1936 & 5373 & 3880 & 14,89 & 95,56 \\
\hline Bameri & 240749 & 170687 & 639 & 4103 & 1193 & 19,08 & 75,56 \\
\hline P. Alegre & 1409351 & 164992 & 1713 & 7959 & 4128 & 20,82 & 91,11 \\
\hline Osasco & 666740 & 139129 & 404 & 6069 & 1059 & 18,67 & 77,78 \\
\hline S. Caatano do Sul & 149263 & 100310 & 324 & 1991 & 477 & 22,35 & 64,44 \\
\hline Curitiba & 1751907 & 99060 & 1860 & 5014 & 3595 & 18,5 & 95,56 \\
\hline Fortaleza & 2452185 & 96203 & 1088 & 3189 & 2134 & 14,28 & 82,22 \\
\hline Recife & 1537704 & 63728 & 1046 & 2598 & 2662 & 21,88 & 84,44 \\
\hline Itajaí & 183373 & 61852 & 319 & 795 & 1134 & 23,37 & 57,78 \\
\hline Mogi das Cruzes & 387779 & 60391 & 168 & 418 & 462 & 18,19 & 53,33 \\
\hline Salvador & 2675656 & 56111 & 962 & 2313 & 2943 & 22,43 & 84,44 \\
\hline São B. do Campo & 765463 & 55659 & 526 & 1541 & 1155 & 19,84 & 71,11 \\
\hline Concórdia & 68621 & 55415 & 94 & 425 & 118 & 6,53 & 48,89 \\
\hline Campinss & 1080113 & 43464 & 871 & 2325 & 2838 & 28,34 & 71,11 \\
\hline Maringá & 357077 & 42339 & 539 & 1284 & 1098 & 12,99 & 62,22 \\
\hline Mansus & 1802014 & 40194 & 436 & 1330 & 1312 & 10,73 & 64,44 \\
\hline Santo André & 676407 & 38992 & 471 & 897 & 1152 & 19,74 & 60 \\
\hline Goiânia & 1302001 & 37151 & 1061 & 2157 & 2083 & 17,09 & 84,44 \\
\hline Guarulhos & 1221979 & 36444 & 648 & 1490 & 1980 & 23,29 & 68,89 \\
\hline Contagem & 603442 & 36100 & 484 & 1212 & 1197 & 19,79 & 71,11 \\
\hline N. Sra do Socorro & 160827 & 34572 & 32 & 401 & 113 & 17,44 & 15,56 \\
\hline Piracicaba & 364571 & 34186 & 278 & 622 & 612 & 13,64 & 62,22 \\
\hline Jundiá & 370126 & 28852 & 320 & 758 & 800 & 26,16 & 64,44 \\
\hline Jaguariúna & 44311 & 28208 & 44 & 187 & 118 & 14,97 & 37,78 \\
\hline Franca & 318640 & 28172 & 185 & 1027 & 378 & 8,51 & 62,22 \\
\hline Cascavel & 286205 & 26212 & 335 & 790 & 596 & 11,73 & 66,67 \\
\hline Londring & 506701 & 26204 & 507 & 1771 & 1090 & 17,36 & 73,33 \\
\hline Belém & 1393399 & 25847 & 437 & 1400 & 1089 & 14,57 & 73,33 \\
\hline Duque de Caxias & 855048 & 25687 & 295 & 697 & 894 & 20,48 & 60 \\
\hline Maceió & 932748 & 24818 & 231 & 441 & 966 & 16,2 & 68,89 \\
\hline Vitória & 327801 & 22258 & 611 & 1624 & 1254 & 28,57 & 77,78 \\
\hline Såo Joâo Meriti & 458673 & 19859 & 165 & 465 & 306 & 17,24 & 51,11 \\
\hline Joinville & 515288 & 19218 & 435 & 1089 & 1118 & 18,6 & 73,33 \\
\hline Chapecó & 183530 & 19079 & 241 & 596 & 459 & 20,72 & 60 \\
\hline Säo Luís & 1014837 & 18753 & 318 & 685 & 1097 & 24,74 & 68,89 \\
\hline Teresing & 814230 & 18435 & 272 & 792 & 745 & 12,24 & 68,89 \\
\hline Natal & 803739 & 18408 & 462 & 957 & 1156 & 16,05 & 68,89 \\
\hline Betim & 378089 & 17836 & 181 & 439 & 542 & 21,36 & 51,11 \\
\hline Florianópolis & 421240 & 17798 & 606 & 1331 & 1371 & 19,39 & 73,33 \\
\hline Niterói & 487562 & 16866 & 340 & 757 & 978 & 17,08 & 73,33 \\
\hline Caxias Sul & 435564 & 16533 & 492 & 1144 & 1018 & 11,71 & 68,89 \\
\hline Ap. de Goiânia & 455657 & 16388 & 276 & 554 & 557 & 12,69 & 60 \\
\hline Uberlândia & 604013 & 16204 & 447 & 1358 & 1113 & 20,78 & 71,11 \\
\hline Ijoctāo Gurerpe & 644620 & 15921 & 254 & 562 & 765 & 23,95 & 55,56 \\
\hline Salto & 105516 & 15704 & 81 & 420 & 135 & 18,61 & 46,67 \\
\hline Araraquara & 208662 & 15543 & 167 & 564 & 392 & 18,67 & 66,67 \\
\hline Blumengu & 309011 & 15542 & 482 & 991 & 910 & 19.29 & 66,67 \\
\hline
\end{tabular}

Nota: empresas controladoras referem-se à empresas-sede oriundas do município listado, controladoras de filiais externas a este município, enumeradas em número de filiais controladas; filiais controladas são filiais fora dos limites do município listado e, por conseguinte, das suas empresas-sede enumeradas em número de empresas controladoras; filiais atraídas são aquelas circunscritas ao município listado, controladas por empresas-sede externas ao mesmo, estas últimas, enumeradas em número de empresas atraídas; os serviços de apoio às empresas são consultorias, auditorias, propaganda, publicidade, seguros, financeiro, etc. (IBGE, 2014, p. 75). Fonte: IBGE, 2014. 
FRESCA, T.M. Londrina como centro de gestão do t território: uma ...

Quanto ao município de Londrina, este se colocava na $30^{a}$ posição no ranking nacional do ponto de vista dos assalariados externos, que representavam $17,36 \%$ sobre o total de assalariados municipais; vale observar ainda a elevada oferta de serviços de apoio às empresas. Os elementos ratificam a continuidade da concentração no Centro-Sul do país em termos de gestão do território, seja pelo número de empresas controladoras, bem como de assalariados externos. Então, qual a correlação entre as transformações na estrutura espacial das grandes empresas e corporações, com esta relativa continuidade - verificada nos estudos anteriormente citados - da concentração em termos de gestão do território? Relativa porque algumas situações vão de encontro com as discussões realizadas anteriormente como é o caso de Londrina, uma cidade que galgou posição na concentração de atividades e poder.

\section{Londrina e as atividades privadas da gestão do território}

A partir dos elementos colocados anteriormente se têm indicativos do papel de Londrina enquanto centro de gestão do território na escala nacional. $\mathrm{O}$ quadro 2 apresenta as principais empresas, filiais, número de assalariados externos e ramos de atividades da cidade em outubro de 2015. A primeira observação refere-se ao fato de que, foram levantadas apenas as principais empresas, cujo total de assalariados externos não corresponde àqueles presentes no quadro 1 . Isso pelo fato de que, foi realizado levantamento apenas das empresas mais destacadas a partir da literatura e de fontes explicadas anteriormente. Desta maneira, o quadro 2 apresenta um total de 15165 trabalhadores externos em 2015, quando em 2011, o IBGE (2014) indicava o total de 26204 trabalhadores. Essa diferença se vincula ao fato de que, várias empresas se negaram a fornecer informações; outras tiveram suas sedes transferidas de Londrina para outras cidades e no limite 
FRESCA, T.M. Londrina como centro de gestão do $t$ território: uma ...

\section{temporal de realização do presente trabalho, a autora não conseguiu identificar outras empresas. \\ Quadro 2: Algumas das Principais Empresas Privadas de Londrina, Ramos de Atividades e Trabalhadores Assalariados Externos, outubro de 2015.}

\begin{tabular}{|c|c|c|c|}
\hline $\begin{array}{l}\text { Empresa } \\
\text { ou Grupo }\end{array}$ & Atividades & Localização das filiais & Trab. externos \\
\hline \multirow[t]{4}{*}{ Plaenge } & $\begin{array}{l}\text { Incorporação e Const. Civil } \\
\text { Resid. }\end{array}$ & $\begin{array}{l}\text { Curitiba, Maringá, Campo Grande, } \\
\text { Dourados, Três Lagoas, Cuiabá, } \\
\text { Joinville, Chile (Região de Araucária; } \\
\text { Região de Los Lagos; Região de Los } \\
\text { Rios) }\end{array}$ & \multirow[t]{4}{*}{2000} \\
\hline & Energia Renovovável & Tamboara - PR & \\
\hline & C. Civil Industrial & Brasil e Venezuela & \\
\hline & Equip. Const. Civil & $\begin{array}{l}\text { Curitiba, Maringá, Campo Grande, } \\
\text { Dourados, Três Lagoas, } \\
\text { Cuiabá, Joinville }\end{array}$ & \\
\hline \multirow[t]{2}{*}{ A. Yoshii } & $\begin{array}{l}\text { Incorporação e Const. Civil } \\
\text { Residencial }\end{array}$ & $\begin{array}{l}\text { Arapongas, Apucarana, Maringá, } \\
\text { Curitiba }\end{array}$ & \multirow[t]{2}{*}{2248} \\
\hline & Construção Civil Industrial & todo o Brasil & \\
\hline Vectra & Construção Civil & $\begin{array}{l}\text { Dourados, Três Lagoas, Londrina, } \\
\text { Porecatu, Curitiba }\end{array}$ & 20 \\
\hline Graúna & Construção Civil & Londrina, Maringá e Três Lagoas & 130 \\
\hline Artenge & $\begin{array}{l}\text { Const. Civil Residencial e } \\
\text { Industrial }\end{array}$ & $\begin{array}{l}\text { Londrina, Arapongas, Rolândia, } \\
\text { Jacarezinho, Apucarana, } \\
\text { Telêmaco Borba, Pres. Prudente }\end{array}$ & 228 \\
\hline \multirow[t]{3}{*}{$\begin{array}{l}\text { Teixeira \& } \\
\text { Holzmann }\end{array}$} & $\begin{array}{l}\text { Incorporação e Loteamentos } \\
\text { Fechados }\end{array}$ & $\begin{array}{l}\text { Foz Iguaçu, Ibiporã; Rondonópolis, } \\
\text { Araçatuba, Vitória, Campos } \\
\text { Goytacazes, Brasília }\end{array}$ & \multirow[t]{3}{*}{255} \\
\hline & Const. Civil Comercial (hotéis) & $\begin{array}{l}\text { Sertanópolis, Londrina, Chapada dos } \\
\text { Guimarães }\end{array}$ & \\
\hline & Fazendas (pecuária bovina) & Icaraíma, Umuarama, Guaraci & \\
\hline Belagrícola & $\begin{array}{l}\text { Comércio de insumos, serviços } \\
\text { à agricultura de grãos, } \\
\text { laboratório para sementes e } \\
\text { solos, recebimento, secagem, } \\
\text { armazenagem, comercialização } \\
\text { de grãos }\end{array}$ & $\begin{array}{l}\text { No Paraná: Alvorada do Sul, Andirá, } \\
\text { Aquidaban, Arapongas, Assaí, } \\
\text { Astorga, Bela Vista do Paraíso, Caixa de } \\
\text { São Pedro, Cambé, Cornélio Procópio, } \\
\text { Correia de Freitas, Ibiporã, Imbituva, } \\
\text { Itambé, Ipiranga, Ivaí, Lapa, Londrina } \\
\text { Lupionópolis, Mauá da Serra, Nova } \\
\text { Fátima, Palmeira, Pitangueiras, Ponta } \\
\text { Grossa, Prado Ferreira, Primeiro de } \\
\text { Maio, Rolândia, Sabáudia, Santa Cecília } \\
\text { do Pavão, Santa Mariana, Sertaneja, } \\
\text { Sertanópolis, Tamarana, Teixeira } \\
\text { Soares, Tibagi; No estado de São Paulo: } \\
\text { Assis, Cândido Mota, Cruzália, } \\
\text { Ibirarema, Ribeirão do Sul, Iepê, } \\
\text { Nantes, Palmital, Assis, Cruzália, }\end{array}$ & 1278 \\
\hline
\end{tabular}


FRESCA, T.M. Londrina como centro de gestão do $t$ território: uma ...

\begin{tabular}{|c|c|c|c|}
\hline & & $\begin{array}{l}\text { Itaberá, Itaporanga, Pilar do Sul, São } \\
\text { Miguel Arcanjo, Ribeirão do Sul; em } \\
\text { Santa Catarina: Canoinhas, Mafra e } \\
\text { Itaiópolis. }\end{array}$ & \\
\hline $\begin{array}{l}\text { Coop. } \\
\text { Integrada }\end{array}$ & $\begin{array}{l}\text { Serviço de apoio a agricultura; } \\
\text { comércio de insumos e } \\
\text { recebimento e armazenagem de } \\
\text { grãos; comercialização de } \\
\text { grãos; indústria de fiação } \\
\text { algodão; beneficiamento de } \\
\text { café, indústria de sucos, } \\
\text { indústria de extração óleo } \\
\text { vegetal (milho), indústria de } \\
\text { ração para animais, silvicultura. }\end{array}$ & $\begin{array}{l}\text { Mauá da Serra, Pinhalão, Assaí, } \\
\text { Cambará, Londrina, Ubiratã, Mauá da } \\
\text { Serra, Cornélio Procópio, Arapongas, } \\
\text { Astorga, Bandeirantes, Goioerê, Guaíra, } \\
\text { Maringá, Urá́, Santa Cecília do Pavão, } \\
\text { Ribeirão Claro, Andirá, Barra do Jacaré, } \\
\text { Bela Vista do Oeste, Cambará, Cambé, } \\
\text { Cascavel, Congonhinhas, Dr. Camargo, } \\
\text { Floresta, Guapirama, Itambaracá, Japira, } \\
\text { Terra Boa, Marialva, Mariluz, Maringá, } \\
\text { Mercedes, Quarto Centenário, Rancho } \\
\text { Alegre, Rancho Alegre do Oeste, } \\
\text { Ribeirão do Pinhal, Santa Amélia, Santa } \\
\text { Fé, Santa Mariana, Santo Antonio do } \\
\text { Paraíso, Rolândia, Tamarana, Ubiratã, } \\
\text { Floraí. }\end{array}$ & 1648 \\
\hline Confepar & Laticínio & $\begin{array}{l}\text { Londrina, Maringá, Nova Londrina, } \\
\text { Mandaguari, Astorga, Porecatu, Pato } \\
\text { Branco, Cascavel, São Lourenço do } \\
\text { Oeste. }\end{array}$ & 51 \\
\hline Agro 100 & $\begin{array}{l}\text { Comércio de insumos, } \\
\text { multiplicação sementes, } \\
\text { serviços à agricultura, } \\
\text { assistência técnica, } \\
\text { recebimento, secagem, } \\
\text { armazenagem e } \\
\text { comercialização de grãos, } \\
\text { terminal rodoferroviário, } \\
\text { difusão tecnológica. }\end{array}$ & $\begin{array}{l}\text { No Paraná: Alvorada do Sul, Assaí, Bela } \\
\text { Vista do Paraíso, Borrazópolis, Cambé, } \\
\text { Londrina, Maringá, Mauá da Serra, } \\
\text { Nova Santa Bárbara, Primeiro de Maio, } \\
\text { Rolândia, Sabáudia, Sertanópolis, São } \\
\text { Jorge do Ivaí, Tamarana; Eldorado, } \\
\text { Ponta Porã e Naviraí - MS; Maracaí e } \\
\text { Iepê- SP }\end{array}$ & 310 \\
\hline $\begin{array}{l}\text { Adama } \\
\text { Brasil }\end{array}$ & Ind. de produtos agroquímicos & $\begin{array}{l}\text { Indústria e Laboratório em Londrina, } \\
\text { Indústria em Taquari - RS, } \\
17 \text { unidades regionais de venda; } 03 \\
\text { centros de distribuição } \\
\end{array}$ & 280 \\
\hline Cacique & $\begin{array}{l}\text { Ind. de café solúvel, torrado e } \\
\text { moído }\end{array}$ & Londrina, Santos, Barueri & 108 \\
\hline Meridional & Indústria de Óleo vegetal & Ponta Grossa, Londrina e Áustria & 48 \\
\hline Fortaleza & $\begin{array}{l}\text { Com. e armazenagem de café } \\
\text { em grãos }\end{array}$ & $\begin{array}{l}\text { Cacoal, Poços de Caldas, Vitória, } \\
\text { Santos, Londrina }\end{array}$ & 80 \\
\hline Bratac & Fiação seda & $\begin{array}{l}\text { Londrina, Bastos - SP e noroeste do } \\
\text { Paraná }\end{array}$ & 139 \\
\hline Deltaplan & Ind. de embalagens plásticas & Londrina e São Bernardo Campo & 05 \\
\hline $\begin{array}{l}\text { Trucks } \\
\text { Control } \\
\end{array}$ & $\begin{array}{l}\text { Ind. de rastreador p/caminhões } \\
\text { tecnologia }\end{array}$ & 76 unidades no Brasil e 01 na Argentina & 316 \\
\hline Viscardi & Supermercados & $\begin{array}{l}10 \text { lojas Londrina; } 01 \text { em Cambé e } 02 \\
\text { Ibiporã }\end{array}$ & 44 \\
\hline Tonhão & Supermercados & Londrina com 07 lojas e Cambé 01 loja & 40 \\
\hline $\begin{array}{l}\text { BR } \\
\text { Consórcio }\end{array}$ & Administradora de seguros & $\begin{array}{l}\text { Foz, Londrina, Paranavaí, BH, Montes } \\
\text { Claros, Ribeirão Preto, Aracaju, } \\
\text { Brasília, Goiânia, Cuiabá, Porto Velho, }\end{array}$ & 320 \\
\hline
\end{tabular}


FRESCA, T.M. Londrina como centro de gestão do t território: uma ...

\begin{tabular}{|c|c|c|c|}
\hline & & Fortaleza, São Luiz & \\
\hline Vale Verde & $\begin{array}{l}\text { Farmácia e laboratório de } \\
\text { manipulação }\end{array}$ & $\begin{array}{l}25 \text { em Londrina, } 03 \text { Cambé, } 02 \\
\text { Arapongas, Rolândia, Ibiporã e } 01 \\
\text { laboratório de manipulação em Londrina }\end{array}$ & 102 \\
\hline Vernie & Concessionária Automóveis & Londrina e Maringá & 17 \\
\hline Metronorte & Concessionária Automóveis & $\begin{array}{l}\text { Londrina } 02 \text { lojas, Joinville, S. J. dos } \\
\text { Pinhais (02 lojas), S. Paulo (03 lojas) e } \\
\text { Paranaguá }\end{array}$ & 450 \\
\hline Nicenter & Concessionária Automóveis & Londrina e Apucarana & 11 \\
\hline Cipasa & Concessionária Automóveis & Londrina, Colorado e Ibiporã & - \\
\hline Copralon & Distribuidor Kibom & $\begin{array}{l}\text { norte do Paraná e estados do MS, MT, } \\
\text { Rondônia, Acre }\end{array}$ & 139 \\
\hline Unimed & Plano de saúde & $\begin{array}{l}\text { Alvorada do Sul, Arapongas, Assaí, } \\
\text { Bela Vista do Paraíso, Cafeara, Cambé, } \\
\text { Centenário do Sul, Colorado, } \\
\text { Florestópolis, Guaraci, Ibiporã, Itaguajé, } \\
\text { Jaguapitã, Jataizinho, Lupionópolis, } \\
\text { Miraselva, Nossa Senhora das Graças, } \\
\text { Pitangueiras, Porecatu, Prado Ferreira, } \\
\text { Primeiro de Maio, Rolândia, Sabáudia, } \\
\text { Santo Inácio, Santa Inês, Sertanópolis e } \\
\text { Tamarana. }\end{array}$ & 400 \\
\hline Labimagem & Laboratório clínico/imagem & Londrina, Cambé, Ibiporã e Rolândia & 17 \\
\hline Uniprime & Cooperativa de Crédito & $\begin{array}{l}\text { Paranavaí, Umuarama, Cianorte, Campo } \\
\text { Mourão, Maringá, Rolândia, Arapongas, } \\
\text { Apucarana, Ivaiporã, Cambé, Londrina, } \\
\text { Santo Antonio da Platina, Jacarezinho, } \\
\text { Curitiba, Paranaguá no estado do } \\
\text { Paraná; Marília, Bauru, Campinas, } \\
\text { Sorocaba - SP. }\end{array}$ & 280 \\
\hline Laborsolo & $\begin{array}{l}\text { Laboratório para análise de } \\
\text { solos }\end{array}$ & Londrina e Toledo & 01 \\
\hline Apetit & $\begin{array}{l}\text { Administradora de } \\
\text { Restaurantes }\end{array}$ & $\begin{array}{l}12 \text { estados do Brasil; regionais em: } \\
\text { Curitiba, São Paulo, Salvador e } \\
\text { Uberlândia. }\end{array}$ & 2000 \\
\hline Veronesi & Hotéis & $\begin{array}{l}\text { Londrina, Cianorte (26 trabalhadores); } \\
\text { Capalbio e Roma (Itália) }\end{array}$ & 26 \\
\hline Thomasi & hotéis & Londrina e Maringá & - \\
\hline Midiograf & Gráfica e editora & $\begin{array}{l}\text { Londrina, Maringá, Curitiba, Campinas, } \\
\text { Cascavel, São Paulo }\end{array}$ & 12 \\
\hline Serilon & $\begin{array}{l}\text { Distribuidor de produtos para } \\
\text { comunicação visual; indústria } \\
\text { de vinis; indústria de Máquinas } \\
\text { Laser p/a corte e gravação de } \\
\text { materiais não metálicos, } \\
\text { máquinas para corte e } \\
\text { soldagem de lonas, lojas } \\
\text { virtuais, call center (assistência } \\
\text { técnica) }\end{array}$ & $\begin{array}{l}\text { Bauru, Belém, B. Horizonte, Blumenau, } \\
\text { Brasília, Campinas, } \\
\text { C. Grande, Cuiabá, Curitiba, } \\
\text { Florianópolis, Fortaleza, Goiânia, } \\
\text { Joinville, Londrina, Maceió, Manaus, } \\
\text { Maringá, Natal, P. Alegre, } \\
\text { P. Velho, R. Janeiro, Rib. Preto, } \\
\text { Salvador, São Luís, S.José Rio } \\
\text { Preto, São Paulo, Teresina, Uberlândia, } \\
\text { Vitória, Guarulhos }\end{array}$ & 502 \\
\hline
\end{tabular}


FRESCA, T.M. Londrina como centro de gestão do $t$ território: uma ...

\begin{tabular}{|c|c|c|c|}
\hline $\begin{array}{l}\text { Garcia } \\
\text { Brasil Sul }\end{array}$ & $\begin{array}{l}\text { Transp. passag., carga, coletivo } \\
\text { e fretamento }\end{array}$ & $\begin{array}{l}\text { Estados do PR, SP, MG, RJ e Região } \\
\text { Metropolitana de Londrina }\end{array}$ & 1006 \\
\hline TIL & Transporte coletivo e Turismo & $\begin{array}{l}\text { Londrina, Cambé e Ibiporã } \\
\text { (metropolitano) e norte do Paraná } \\
\text { (fretamento/turismo) }\end{array}$ & - \\
\hline $\begin{array}{l}\text { Imperial } \\
\text { Móveis }\end{array}$ & $\begin{array}{l}\text { Com. de móveis e } \\
\text { eletrodomésticos }\end{array}$ & $\begin{array}{l}\text { Londrina, Cambé, Assaí, São Jerônimo } \\
\text { da Serra, Congonhinhas, } \\
\text { Primeiro de Maio, Bela Vista do } \\
\text { Paraíso, Alvorada do Sul }\end{array}$ & 20 \\
\hline Movelar & $\begin{array}{l}\text { Com. de móveis e } \\
\text { eletrodomésticos }\end{array}$ & $\begin{array}{l}\text { Cambé, Londrina, Alvorada do Sul, } \\
\text { Bela Vista do Paraiso, Primeiro de Maio }\end{array}$ & 25 \\
\hline Casas Ajita & Com. de calçados & $\begin{array}{l}\text { Londrina, Maringá, Paranavaí, Foz do } \\
\text { Iguaçu, Rolândia, Ibiporã, } \\
\text { Arapongas, Ibiporã, Apucarana, } \\
\text { Cascavel ( } 31 \text { lojas) }\end{array}$ & 280 \\
\hline $\begin{array}{l}\text { Móveis } \\
\text { Brasília }\end{array}$ & $\begin{array}{l}\text { Com. de móveis e } \\
\text { eletrodomésticos }\end{array}$ & $\begin{array}{l}\text { Londrina, Balneário Camboriú, Itajaí, } \\
\text { Blumenau, Arapongas, } \\
\text { Cornélio Procópio, Nova Fátima, Santa } \\
\text { Mariana, Uraí, } \\
\text { Congonhinhas, São Sebastião da } \\
\text { Amoreira, Maringá, Ibiporã, } \\
\text { Cascavel, Cambé. }\end{array}$ & 176 \\
\hline Conasa & Saneamento básico & $\begin{array}{l}\text { Itapema - SC; Santo Antônio de Pádua } \\
\text { - RJ, Salto - SP }\end{array}$ & 180 \\
\hline Econorte & Concessionária rodovia & $\begin{array}{l}\text { Porção leste do norte do Paraná (de } \\
\text { Cambará a Cambé) }\end{array}$ & - \\
\hline $\begin{array}{l}\text { Sávio } \\
\text { Sorvetes }\end{array}$ & Indústria de sorvetes & $\begin{array}{l}\text { Marília - SP, Várzea Grande MT } \\
\text { (distribui produtos no estado do Paraná, } \\
\text { Santa Catarina, São Paulo, Mato Grosso } \\
\text { do Sul e Mato Grosso }\end{array}$ & - \\
\hline $\begin{array}{l}\text { Mister } \\
\text { Cuca }\end{array}$ & Padaria e Confeitaria & Maringá & - \\
\hline $\begin{array}{l}\text { Grupo } \\
\text { Seven }\end{array}$ & $\begin{array}{l}\text { Agropecuária, taxi aéreo, } \\
\text { indústria farmacêutica, } \\
\text { securitizadora }\end{array}$ & Londrina, Centenário do Sul, Ibiporã & 59 \\
\hline
\end{tabular}

- dados não fornecidos pelas empresas. Fonte: Sítio das empresas, out. 2015 e levantamento de campo, 2015. Org.: Fresca, T. M., 2015.

O quadro deixa evidente o predomínio de alguns setores nos quais se tem maior número de assalariados externos como a construção civil, empresas vinculadas aos agronegócios, serviços diversos e atividades comerciais varejistas. Existem ainda outras empresas que realizam a gestão do território e que não estão presentes no quadro 2 . São unidades de negócios de corporações de capitais internacionais presentes em Londrina, não tendo nessa a sua sede e nem sempre apresentam assalariados externos, mas seu poder é significativo: Bemis 
FRESCA, T.M. Londrina como centro de gestão do t território: uma ...

Latin America (indústria no segmento de embalagens plásticas) e Atlas Schindler (indústria produtora de elevadores, esteiras e escadas rolantes); a Adama Brasil (segmento agroquímico) tem sua sede nacional em Londrina e apresenta assalariados externos. Mas envolve ainda uma empresa do segmento supermercadista, cuja gestão se realiza em parte, a partir da cidade de Londrina.

Principia-se pelas empresas vinculadas aos agronegócios ${ }^{3}$. Utiliza-se aqui o termo no plural para deixar explícito que se trata de vários segmentos: leite e derivados através da Confepar AgroIndustrial Cooperativa Central; Integrada Cooperativa Agroindustrial, que atua em diferentes ramos: industrial, comercial, serviços, silvicultura, etc.; Belagrícola e Agro 100 atuando como provedora de soluções em todas as etapas da agricultura: preparo de solo e plantio; monitoramento da lavoura, fornecimento e aplicação de insumos de alta tecnologia; colheita, armazenagem e comercialização de safra, dentre outras presentes no quadro 2. Assim, os agronegócios são entendidos como:

[...] a cadeia produtiva que envolve desde a fabricação de insumos, passando pela produção nos estabelecimentos agropecuários e pela transformação, até seu consumo. Essa cadeia incorpora todos os serviços de apoio: pesquisa e assistência técnica, processamento, transporte, comercialização, crédito, exportação, serviços portuários, distribuidores (dealers), bolsas, e o consumidor final (CONTINI et. al., 2006, p. 6).

São empresas cuja atuação centrada em produtos e processos para a agropecuária, realizam a gestão do território de modo muito amplo em vários aspectos, não apenas pelos assalariados externos.

3 Diante da quantidade de empresas levantadas para a cidade de Londrina, o texto não apresenta detalhamento de todas; fez-se a opção de dar alguns elementos daquelas que mais se destacam, seja pelo número de assalariados externos, por realizar gestão do território sem que a cidade seja a sede social da mesma, ou pelo fato de apresentar formas de gestão bastante diferenciadas. 
FRESCA, T.M. Londrina como centro de gestão do t território: uma ...

Para este último elemento ocorre importante drenagem da mais valia, direcionados para a sede, a partir da qual se tomam decisões de novos investimentos produtivos, de expansão de área de atuação, abertura de novas atividades, dentre outros.

$\mathrm{Na}$ realidade essas empresas, que tem sob seu comando parcela de atividades de cadeias mercantis globais (ESPÍNDOLA, 2015) de soja, milho, trigo, leite, café, dentre outros, impõem decisões aos produtores rurais em termos de continuidade ou não de determinadas produções; impõem preços aos produtos agrícolas - evidente que articulados à dinâmica das bolsas de valores mundiais; realizam expressivo controle da comercialização de grãos. Nesta última etapa, empresas de capitais internacionais como a Cargill, Bunge, Louis Dreyfus, etc. não tem importância, já que aquelas de capital nacional e atuação regional têm controle do mercado. Em linhas gerais, o norte do estado do Paraná tem papel relevante na produção de soja, milho, trigo; criação e processamento de frangos, leite e derivados e sucroalcooleiro; além de outras produções agropecuárias que tem menor destaque em termos de área, trabalhadores e receitas como é o caso da fruticultura, mandioca, sericicultura (Bratac), etc.

Esta participação na divisão territorial do trabalho insere o norte do estado (não exclusivamente porque, quase todo o estado tem papel relevante na produção agropecuária) em cadeias mercantis globais, bem como apresenta importante papel no processamento de parte destas produções. No entanto, a agropecuária participou no PIB paranaense com cerca de $7 \%$ e $9,2 \%$ no valor adicionado bruto em 2012 (IPARDES, 2012); as exportações do estado em 2014 tiveram o predomínio de produtos e subprodutos processados da agricultura (soja, carne, cana de açúcar, milho), com exceção dos automóveis com motor (FIEP, 2015). Se o processamento dos produtos agropecuários ainda não é maior, isto se vincula à promulgação da Lei Kandir na gestão FHC, que causou enormes prejuízos do ponto de vista do engessamento da expansão da transformação industrial da produção agrícola. Isto pelo fato de isentar de impostos as exportações 
FRESCA, T.M. Londrina como centro de gestão do $t$ território: uma ...

de produtos primários e semimanufaturados, significando que, empresas que poderiam ampliar a transformação de produtos agrícolas, são desestimuladas. Gera-se e amplia-se a capacidade ociosa (RANGEL, 2005) industrial e as empresas transferem até certo ponto, esta capacidade de investimentos para outras áreas e atividades.

A essas empresas e em parte por vincularem-se à produção agropecuária, acrescente-se a Adama Brasil, integrante da corporação Adama Agricultural Solutions, controlada em $60 \%$ pela estatal Chen China e $40 \%$ pela holding israelense IDB. Esta corporação atua no Brasil no ramo agroquímico, cuja sede nacional e uma unidade produtiva estão em Londrina, contando com 280 assalariados externos, distribuídos em outra planta localizada em Taquari (RS) (90 trabalhadores) e os demais entre as 17 regionais de venda e 03 centros de distribuição. Esta unidade de negócios no Brasil gerava 15\% dos negócios globais da corporação; colocavase como $380^{a}$ posição no ranking das 1000 maiores empresas no Brasil em 2015 (VALOR ECONÔMICO, 2015).

Ser a sede nacional desta empresa é compreensível pelo fato de que, o segmento de agroquímicos tem no Centro-Sul do país seu principal mercado consumidor; a localização da cidade em relação a esta ampla área é favorável, além da infraestrutura disponível; o fato da cidade sediar o principal centro brasileiro de pesquisa da soja, Embrapa Soja, sediar o Instituto Agronômico do Paraná que efetua inúmeras pesquisas; mas vincula-se ainda a um processo histórico da criação de uma empresa de adubos nos anos de 1970 na cidade, que passou a pertencer a esta corporação.

Do ponto de vista da estrutura empresarial e articulações com a gestão do território, verifica-se que as empresas e grupos vinculados aos agronegócios, apresentam uma estrutura hierárquica: a sede social é responsável pelo controle e planejamento estratégico; como há relações diretas com a produção propriamente dita, o que implica relações com as condições naturais, transporte, armazenamento, etc., a localização das unidades de fornecimento de insumos/serviços e indústrias, é muito 
FRESCA, T.M. Londrina como centro de gestão do $t$ território: uma ...

diferenciada; no geral, há tendência a manutenção da estrutura hierárquica de gestão empresarial. Convém assinalar que, outras empresas vinculadas aos agronegócios podem apresentar similaridades com os apontamentos de Pred (1979) no que se refere à gestão e relações com as cidades.

Os esquemas 1 e 2 e o mapa 1 demonstram aspectos do processo de integração territorial e gestão de duas empresas do segmento dos agronegócios. Todos os esquemas foram elaborados a partir de Corrêa (2010).

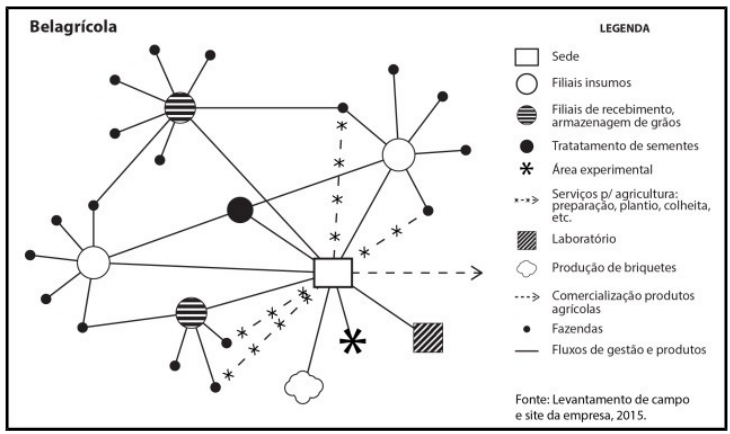

Esquema 1: Integração Territorial da Gestão da Belagrícola, 2015

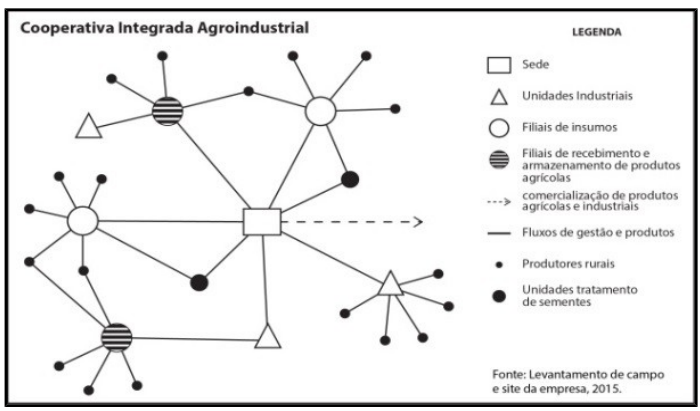

Esquema 2: Integração Territorial da Gestão da Cooperativa Integrada Agroindustrial, 2015 
FRESCA, T.M. Londrina como centro de gestão do t território: uma ...

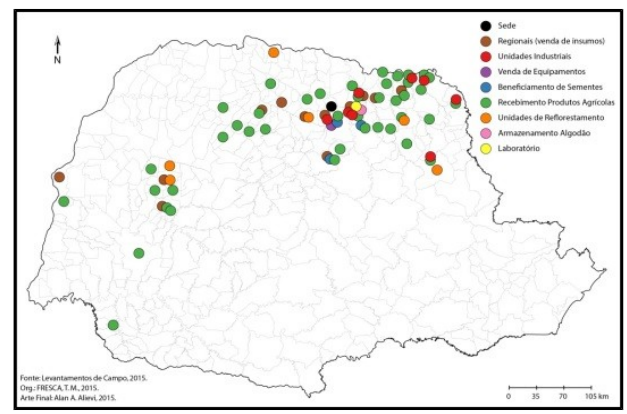

Mapa 1: Localização das unidades da Cooperativa Integrada, 2015.

O mapa 1 com a localização das unidades dessa cooperativa, dá a possibilidade de vislumbrar uma série de interações espaciais em termos de produtos agrícolas e industriais. As unidades de venda de insumos, em número de 14, são responsáveis pela comercialização dos mesmos em toda a área de atuação da empresa. A partir da aquisição dos produtos, realizadas pela sede, os mesmos são distribuídos às suas regionais e a partir dessas, aos produtores rurais. O mesmo ocorre com as três unidades de beneficiamento de sementes, cujos produtos são distribuídos para as regionais. Outro tipo de interações espaciais ocorre com os produtos agrícolas in natura, que a partir das unidades de recebimento (mais de 40) tem vários destinos: para as unidades industriais da cooperativa (e após processamento são comercializados no mercado interno brasileiro); para comercialização no mercado interno (o que inclui várias indústrias); venda para o mercado externo e para a qual, os produtos são direcionados para o Porto de Paranaguá. A venda de máquinas e equipamentos agrícolas realiza-se apenas em Londrina (pela sede), demonstrando interações espaciais centralizadas multidirecionais.

O segundo setor com importância do ponto de vista da gestão do território em Londrina é a construção civil. Gerava cerca 
FRESCA, T.M. Londrina como centro de gestão do t território: uma ...

de 4.800 empregos externos em outubro de 2015, número esse bastante oscilante já que vinculado à dinâmica do setor. O setor tem destaque regional e nacional, comportando algumas das maiores empresas da Região Sul do país. Ainda há outras de menor porte e atuação mais restrita em termos de área como a Artenge, Protenge, Graúna, Dinardi, etc., mas que integram um importante setor na cidade. Sobre as construtoras de Londrina há bibliografia como pode ser verificado em Passos (2007), Nascimento (2015), dentre outros.

A história do desenvolvimento deste setor na cidade ocorre desde os anos de 1950, quando as primeiras empresas de construção civil foram criadas para atuar na produção de edifícios altos. Esse processo não foi interrompido até o presente momento, mas apresentou muitas variações do ponto de vista das construtoras e incorporadoras que atuaram ao longo do tempo como pode ser verificado em Fresca e Oliveira (2015). Dentre as que mais geravam assalariados externos, tem-se o Grupo Plaenge e Grupo A. Yoshii, ambos de capital local e criadas nos anos de 1970 e 1960 respectivamente ${ }^{4}$. O primeiro apresentou evolução em direção à mais ampla diversificação de atividades, envolvendo além de incorporadora e construtora residencial, atuação na área industrial e no século XXI iniciou atividades para geração de energia e adubos a partir da cana de açúcar, bem como atuação no Chile com incorporação e construção residencial. Esse grupo ocupava a $4^{\mathrm{a}}$ posição dentre os maiores da Região Sul e $37^{\text {a }}$ do país conforme $\mathrm{O}$ Empreiteiro (2015) em receita bruta; o grupo A. Yoshii figurava como $7^{\mathrm{a}}$ e $46^{\mathrm{a}}$ nas escalas citadas anteriormente ${ }^{5}$.

4 Há bibliografia sobre a evolução dessas empresas que pode ser verificado em Passos (2007), Nascimento (2015), Fresca; Oliveira (2015) e no sítio das empresas, dentre outras.

5 Nesses dados não estão inclusos as posições de outras empresas desses grupos como a Vanguard Home ( Plaenge) e a Yticon (A. Yoshii). Para detalhamentos, consulte-se: http://oempreiteiro.com.br/Conteudo/19/ ranking-da-engenharia-brasileira.aspx 
FRESCA, T.M. Londrina como centro de gestão do $t$ território: uma ...

Os levantamentos de campo permitiram verificar que, dentre as empresas da construção civil presentes no quadro 2, ocorre divisão do trabalho entre elas, onde cada uma atua em nichos de mercados e em diferentes escalas espaciais. Verifica-se ainda uma estrutura empresarial com tendência a forte centralização com as decisões em termos de investimentos, expansão, locais de atuação, definição da incorporação e construção, emanadas da sede social conforme esquema 3.

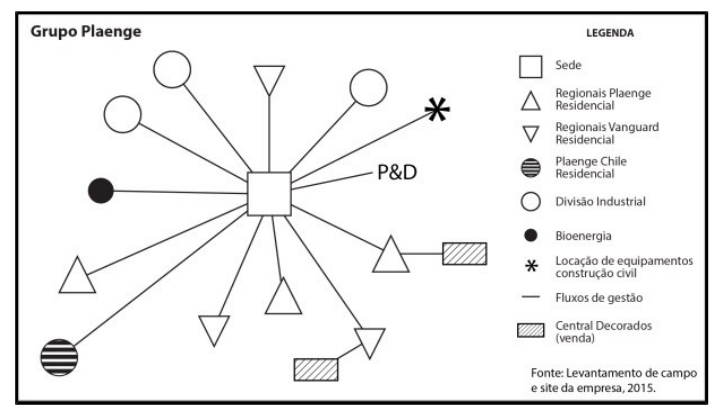

Esquema 3: Integração Territorial da Gestão do Grupo Plaenge, 2015

A especificidade de sua produção, contudo, resulta em que, parcela das atividades como contratação de força de trabalho e obtenção de algumas matérias-primas pode ser obtida nas cidades onde se localizam os empreendimentos.

$\mathrm{O}$ setor industrial comparece com pequeno destaque do ponto de vista da gestão do território, manifestando a relativa fraqueza do mesmo na cidade. Poucas são as empresas com filiais externas; os destaques ficam por conta da Adama Brasil já referida, Cacique Café Solúvel, Meridional TCS, Bratac, Deltaplan, Trucks Control, Serilon e Sávio Sorvetes. São empresas que atuam em diferentes ramos como alimentício, passando por embalagens plásticas, fiação de seda, indústria de vinis, de máquinas laser para corte e gravação de materiais não metálicos, dentre outros. Este setor é caracterizado pelo predomínio de micro e pequenas 
FRESCA, T.M. Londrina como centro de gestão do t território: uma ...

empresas na cidade (SAAB, 2014). Embora não se tenha os dados completos para todas as empresas listadas no quadro 2, o número de assalariados externos (excluso aquelas vinculadas aos agronegócios) é superior a 1400 trabalhadores. Destaque para o Grupo Serilon pela escala de atuação e diversificação de atividades conforme mapa 2 e quadro 2.

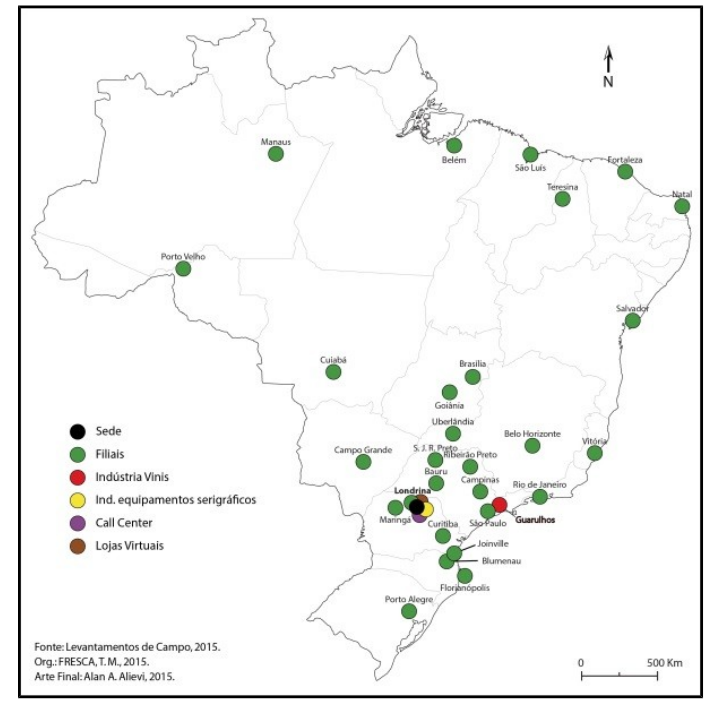

Mapa 2: Localização das Unidades do Grupo Serilon, 2015

No entanto, é necessário acrescentar que as unidades de negócios de corporações internacionais que se localizam em Londrina, embora não tenham a sede das mesmas na cidade, realizam parcela da gestão do território: Bemis Latim America e Atlas Schindler. A primeira possui a sede para a América Latina na cidade de São Paulo e 10 unidades produtivas no Brasil, das quais uma em Londrina produzindo embalagens flexíveis e rígidas. Essa unidade é a maior em número de funcionários e produção e a segunda maior de toda a corporação estabelecida em inúmeros 
FRESCA, T.M. Londrina como centro de gestão do t território: uma ...

países. Nessa tem-se uma fábrica de tintas, duas de flexíveis e uma de rígidos, permitindo entender a importância da mesma para a corporação conforme esquema 4.

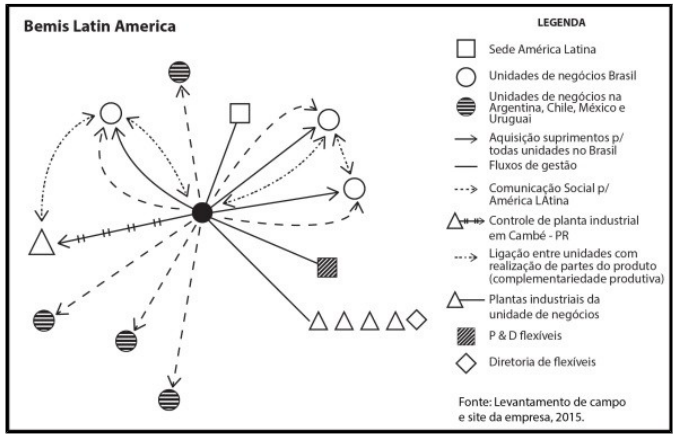

Esquema 4: Integração Territorial da Gestão da Unidade de Negócios da Bemis Latin America em Londrina, 2015

Essa unidade é responsável pela aquisição de suprimentos (matérias primas, material de consumo) para todas as unidades do Brasil; toda a comunicação social para a América Latina; de ter nela a presença do diretor do segmento de flexíveis da corporação, que a partir de Londrina, realiza suas atividades no país; é a partir dela que se tem o controle de planta na cidade de Cambé integrante da aglomeração urbana de Londrina. Vale observar no esquema 4 as ligações entre as unidades presentes no país, no que respeita à produção propriamente dita. Em outros termos, a produção de um dado produto impõe por vezes, ligações entre as unidades para obtenção de partes, peças, produtos destinados à elaboração final.

Neste sentido, avança-se em direção a entender que a gestão do território não se realiza somente a partir de assalariados externos (critério disponível), mas também por outros aspectos identificados nas pesquisas de campo. Em outras palavras, o poder 
FRESCA, T.M. Londrina como centro de gestão do t território: uma ...

de gestão do território não se limita apenas a este critério, posto que, adquirir matérias primas, contratar trabalhadores, estar íntima e diretamente relacionada à dinâmica econômica das vendas no mercado consumidor do continente americano, influi em suas atividades e representa ampliação de seu poder. No entanto, a mensuração desta importância é difícil.

As empresas prestadoras de serviços contribuem com 4230 assalariados externos, mas que envolve número muito maior porque várias empresas de diferentes ramos de atividades, também apresentam empresas ou atividades prestadoras de serviços em sua estrutura empresarial. Veja a Trucks Control, uma indústria que produz rastreadores para caminhões, mas conta com call center próprio e rede de oficinas de apoio aos motoristas no Brasil.

Em termos de assalariados externos, destaque-se a Apetit Serviços de Alimentação e Grupo Garcia Brasil Sul, atuando como administradora de restaurantes e transporte rodoviário de passageiros respectivamente. A Apetit apresenta regionais em Curitiba, São Paulo, Salvador e Uberlândia, a partir das quais, realiza o controle administrativo dos restaurantes presentes em 12 estados brasileiros (APETIT, 2015). Sua estrutura administrativa também é centralizada, cujas regionais, com parcela de poder de comando, estão em metrópoles e grandes cidades, a partir das quais, exercem as atividades finais de administrar os restaurantes em diferentes cidades, muito similar ao colocado por Pred (1979). Nota-se a similaridade com uma estrutura solar.

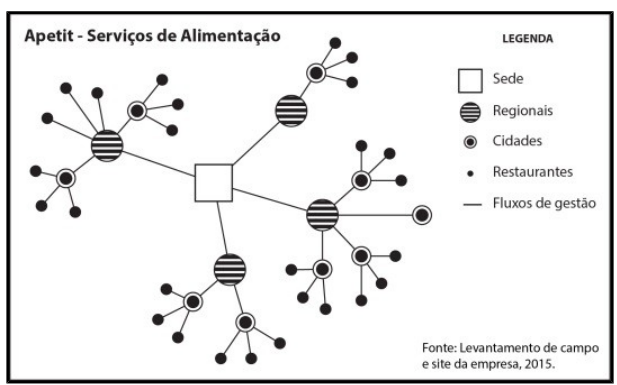


FRESCA, T.M. Londrina como centro de gestão do $t$ território: uma ...

Esquema 5: Integração Territorial da Gestão da Apetit Serviços de Alimentação, 2015

A Uniprime Cooperativa de Crédito é uma das cooperativas que integram o sistema nacional de cooperativismo de crédito no Brasil, situado em setembro de 2015 como o sexto maior do país (PORTAL DO COOPERATIVISMO FINANCEIRO, 2015). Como tal, realiza quase todas as operações de um banco comercial. Fundada em 1997 em Londrina, em 2015 havia atingido mais de 16 mil cooperados entre médicos e outros profissionais liberais e empresas; mais de um bilhão de reais em recursos administrados; número próprio para compensação de cheques; distribuía fundos de investimentos para seus cooperados desde 2006; associada ao Fundo Garantidor do Cooperativismo, instituído pelo Banco Central do Brasil; contava com 25 agências no estado do Paraná e 04 no estado de São Paulo; 03 plataformas, isto é, agências virtuais cujo funcionário da empresa vai pessoalmente ao atendimento de grandes empresas.

No comércio varejista se tem a presença de quatro concessionárias de veículos de diferentes marcas, cujas filiais localizam-se predominantemente em cidades da Região Metropolitana de Londrina. Exceção é a Metronorte, cuja atuação é mais ampla e maior número de assalariados externos. Todas apresentam uma estrutura empresarial bastante simplificada e a gestão do território se realiza mediante fluxos de peças e veículos novos e usados entre as filiais; exceção é a mais valia obtida, direcionada para a sede, a partir da qual se tomam decisões diversas.

Mas é neste setor que se encontram situações bastante distintas do que até o momento se colocou. São redes de pequenas empresas de móveis e eletrodomésticos, aqui representadas pela Imperial Móveis e Movelar Móveis. Essas empresas atuam em pequenas cidades próximas a Londrina, conforme quadro 2, cuja expansão foi determinada predominantemente pelo mercado consumidor. Em outros termos, o comércio varejista de móveis e 
FRESCA, T.M. Londrina como centro de gestão do t território: uma ...

eletrodomésticos conta com grandes empresas e corporações que atuam em Londrina, impondo uma concorrência muito acentuada para pequenos estabelecimentos do mesmo ramo. No entanto, as empresas citadas, expandiram suas atividades mediante abertura de filiais em pequenas cidades. Diante de mercado consumidor extremamente segmentado, a oferta de produtos básicos em termos de móveis e eletrodomésticos acaba por ser consumido na cidade local. Tem-se aqui estrutura empresarial extremamente hierarquizada, cuja sede realiza a compra e distribuição dos produtos e gerencia todas as atividades das filiais e não possuem site, apenas blogs ou página em rede social para comunicação.

Menção deve ser dada ao Grupo Muffato ${ }^{6}$ que apresenta uma estrutura administrativa bastante complexa, aqui denominada de compartilhada, cuja gestão do território se realiza a partir de três cidades. Trata-se de um Grupo que tem na atuação supermercadista seu mais importante segmento, cuja sede está em Cascavel (PR), sendo comandado pela família composta por 3 filhos e a mãe, não constando no quadro 2. Na divisão do trabalho familiar, um filho reside em Cascavel (PR), sendo responsável pelas atividades de planejamento e expansão das filiais da rede supermercadista, cuidando diretamente das obras de construção civil; outro filho é responsável pela coordenação geral das lojas na região metropolitana de Curitiba, onde reside; a mãe reside em Londrina e é a responsável pela aquisição de todos os produtos de bazar; o

6 Em 2015 o Grupo era formado por 45 supermercados no Paraná, 5 no oeste do estado de São Paulo; 03 postos de gasolina; 02 atacados em Cambé (cidade da aglomeração urbana de Londrina) a partir dos quais é realizada a distribuição das mercadorias para todas as filiais; 08 cash \& carry (denominado de atacarejo pela quantidade comercializada); 02 emissoras de TV afiliadas da Rede Bandeirantes: uma em Cascavel e outra em Londrina, com geração de 3 a 4 horas de programação local cada; 01 emissora de rádio em Cascavel; a universidade corporativa do Grupo - Uniffato; a unidade de e-commerce, denominada de Shopfato e as fazendas (GRUPO MUFFATO, 2015). 
FRESCA, T.M. Londrina como centro de gestão do t território: uma ...

filho mais velho reside em Londrina e é responsável pela área comercial e financeira de todas as atividades do Grupo Muffato. Diálogos informais com diversas pessoas ligadas ao Grupo permitiram entender que, as decisões finais ou mais importantes, emanam de Londrina. Então, como fica a gestão do território, quando o poder efetivamente se realiza em uma cidade, mas os dados referem-se a outra? Eis mais um complicador para as análises. $\mathrm{O}$ esquema 6 demonstra aspectos da integração territorial e de gestão do Grupo Muffato.

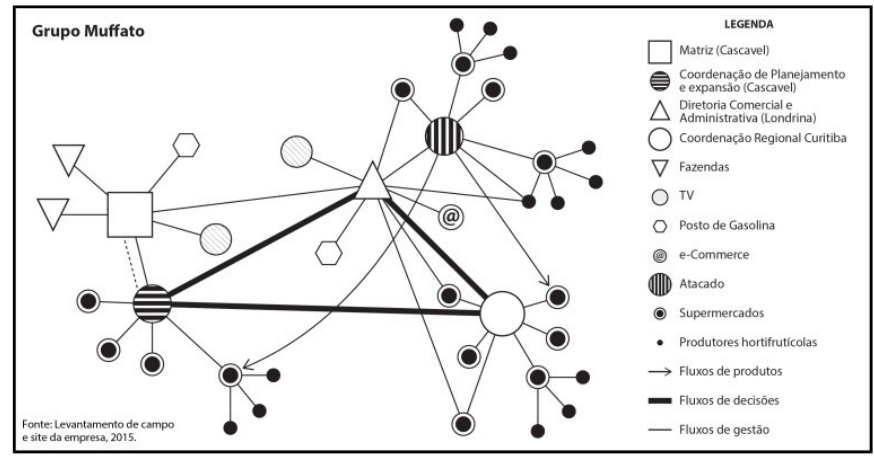

Esquema 6: Integração Territorial da Gestão do Grupo Muffato, 2015

\section{Considerações finais}

A gestão do território realizada por empresas privadas sediadas em Londrina se destaca nos segmentos dos agronegócios (comércio, serviços e indústria), no setor da construção civil e prestador de serviços, enquanto o industrial tem discreta participação.

Do ponto de vista temporal, é difícil precisar uma data em que o papel de gestão do território passou a ser mais importante. Trata-se de identificar um tempo em que a cidade passou do estágio de importante núcleo regional para a condição de núcleo urbano com empresas que apresentem filiais e assalariados 
FRESCA, T.M. Londrina como centro de gestão do $t$ território: uma ...

externos, enquanto critérios aqui utilizados, que possibilitaram a realização desse poder em outra escala. A partir dos anos de 1980 é que se pode identificar tal papel com maior representatividade, momento a partir do qual, empresas foram sendo criadas e/ou as existentes adentraram em expansão, com abertura de filiais, conquistando outros mercados consumidores, por caminhos como investimentos em inovações em produtos, processos, estratégias diferenciadas de mercado consumidor, além do apoio estatal.

As empresas apresentam diversidade de estruturas administrativas: unidades de negócios de corporações com relativo poder de gestão; grupos familiares com forte centralização do poder e gestão; sedes nacionais e internacionais, concentrando todas as decisões. A diversidade de estruturas se vincula por um lado, ao tipo de atividades realizadas, e por outro, denota assimetria em relação à administração, implicando que não se realize apressadamente generalizações das grandes corporações para todas as empresas, porque entre as primeiras também há diferenças.

A gestão do território por uma cidade pode ser realizada sem que a mesma seja sede de corporações ou empresas e nem apresentar assalariados externos. Isso ocorre por diferentes atividades. Para atividades industriais há duas situações. A primeira quando em uma cidade se tem unidades de negócios de corporações internacionais com autonomia administrativa; podendo ser responsável por atividades chaves como pesquisa e desenvolvimento de determinado segmento produtivo em escala nacional; ser responsável pela aquisição de matérias primas para todas as unidades da corporação presentes no país; realizar a comunicação social na escala da América Latina. Uma segunda possibilidade de gestão no setor industrial pode ocorrer quando uma corporação internacional tem uma única unidade industrial na escala nacional que realiza produção; essa unidade localiza-se em cidade que não é a sede social; apresenta sistema organizacional toyotista onde a terceirização atinge cerca de $70 \%$ para obtenção de 
FRESCA, T.M. Londrina como centro de gestão do t território: uma ...

partes e peças. A gestão? É realizada mediante controle sobre os terceirizados, predominantemente externos à unidade produtiva, em direção a administrar a fidelidade dos mesmos. A acumulação é realizada na cidade onde se tem a produção, bem como parcela da pesquisa e desenvolvimento, mas o controle hierárquico é realizado pela sede nacional. No caso de grupos ou empresas comerciais que realizam a gestão do território a partir de cidades que não são sede dos mesmos, isso se realiza mediante decisões de investimentos, áreas de atuação, inovações em processos, controle de aquisição de mercadorias para todas as filiais de um grupo, controle de informações para rede de televisão aberta, dentre outros.

Outra forma de gestão do território é realizada por empresas sediadas na cidade, com filiais e assalariados externos de diferentes setores, denotando-se três formas principais. A primeira dada pela cidade ser sede de corporação de capital internacional, ter uma unidade produtiva industrial, toda a pesquisa e desenvolvimento, controlar todas as decisões de investimentos e da produção propriamente dita, etc. na escala nacional e controlar unidades produtivas localizadas em outras cidades. Aqui se tem articulações diretas com a escala internacional, mediante cidades em diferentes países onde estão as sedes de suas controladoras. Uma segunda forma ocorre quando empresas de capital local são multifuncionais e multilocalizadas, com estrutura empresarial centralizada na sede e atuação em atividades industriais, comerciais e de serviços. Nesse caso envolve empresas do segmento dos agronegócios, de comunicação visual, taxi aéreo, securitizadora; c) empresas e/ou grupos de capital local com atuação em uma única atividade, envolvendo predominantemente atividades comerciais $\mathrm{e}$ prestadoras de serviços e algumas industriais. Todas se apresentam centralizadas, mas com gerências regionais com alguma parcela de autonomia diante da especificidade da atividade.

A gestão do território realizada por Londrina tem diferentes escalas de atuação: internacional, nacional, passando pela macrorregional e regional. A escala internacional apresenta 
FRESCA, T.M. Londrina como centro de gestão do $t$ território: uma ...

situações diversas, porque no que tange à sua inserção em cadeias mercantis globais é intensa, enquanto na produção industrial é menor. Mas demonstra formas diferenciadas de como a internacionalização se realiza, atingindo e se adaptando à cidade. $\mathrm{Na}$ escala nacional sua atuação se realiza por intermédio de algumas atividades industriais, comerciais e de serviços (consórcios, máquinas e equipamentos serigráficos, material para comunicação visual, etc.). É na escala macrorregional e regional que sua atuação é mais evidente.

Na contrapartida, também ocorre a gestão do território por pequenas redes comerciais varejistas, cuja escala de atuação está centrada em cidades da região metropolitana de Londrina, demonstrando a complexidade desta dimensão da realidade, ainda pouco conhecida.

Em realidade, são empresas de origem local que ascenderam à posição de nacional e regional em termos de produção e mercado consumidor, fruto de investimentos locais em uma formação social baseada em pequenas propriedades urbanas e rurais. Ao mesmo tempo, unidades de negócios foram atraídas pela infraestrutura, serviços de comunicação, mão de obra qualificada, mercado consumidor, sindicatos pouco atuantes, pesquisa e desenvolvimento, cursos técnicos, superiores e pós-graduação, presença de fornecedores industriais, apoio do poder público local.

Neste sentido, há que se referir aos fatores internos da formação social, como recursos ao entendimento de caminhos através dos quais unidades de corporações ou grandes empresas instalaram-se e/ou expandiram suas atividades a partir de Londrina. Como entender o fato de uma corporação presente nessa cidade, ter toda a sua comunicação social para a América Latina sendo nela realizada? Não se trata de um serviço quaternário típico da metrópole? Então como em Londrina se realiza? A resposta obtida foi simples: há condições tecnológicas e de mão de obra altamente especializada e qualificada para tal atividade. Isso decorre de fatores internos da formação social e vinculados ao ensino 
FRESCA, T.M. Londrina como centro de gestão do $t$ território: uma ...

superior, médio e fundamental presente, além de infraestrutura, apoio estatal, etc. Da mesma maneira, como pode em área de forte produção de commodities não se ter presença importante de corporações internacionais atuando? Novamente se recorre à capacitação de agentes sociais de diversas origens em termos profissionais, da percepção em entender e capturar processos gerais para sua realização singular na cidade. Sugere-se aqui a realização de pesquisas para desvendamento de práticas espaciais de empresas locais para controle da produção e comercialização da soja, trigo e milho.

O mesmo vale para as grandes incorporadoras e construtoras civis, cuja evolução as coloca com capacitação técnica, administrativa, de inovações em processos, competindo e ganhando concorrência com grandes incorporadoras nacionais e internacionais, que adentraram no mercado local a partir da implantação da legislação federal sobre o Sistema Financeiro Imobiliário (1997). Eis aqui formas através das quais ocorrem adaptações e ajustes na dinâmica empresarial e suas articulações com a gestão do território e a formação social.

São mais de 15 mil trabalhadores externos controlados por empresas de Londrina e isso implica enorme mobilização de mais valia e rendas. Esse é um dos caminhos através dos quais se compreende aspectos da dinâmica econômica da cidade e sua posição no PIB nacional.

Por outro lado, o poder de gestão do território tem sua maior concentração em metrópoles e cidades de suas regiões metropolitanas. Mas parcela desse poder está em cidades de outro escalão urbano, oriundo de diferentes processos em decorrência das transformações que afetaram o país e a economia mundial nas últimas décadas.

\section{Referências bibliográficas}


FRESCA, T.M. Londrina como centro de gestão do $t$ território: uma ...

APETIT SERVIÇOS DE ALIMENTAÇÃO. Nossa história. Disponível em: < http://www.apetit.com.br/nossa-historia $>$. Acesso em outubro de 2015.

BRITO, Cristóvão. A Petrobrás e a gestão do território no Recôncavo Baiano. EDUFBA: Salvador, 2008.

CANTWELL, John (Ed). Location of international business activities: integrating ideas from research in international business, strategic, management and economic geography. N. York: Rutger University, 2014.

CHESNAIS, François. A mundialização do capital. São Paulo, Xamã, 1996.

CONTINI, E. et al. Evolução recente e tendências do agronegócio. Revista de Política Agrícola, Brasília, v. 15, n. 1, 2006, p. 5-28.

CORDEIRO, H. K. Os principais pontos de controle da economia transacional no espaço brasileiro. Boletim de Geografia Teorética, Rio Claro, v. 16-17, n. 31-34, 1987.

CORIAT, B. Pensar pelo avesso: o modelo japonês de trabalho e organização. Rio de Janeiro: Revan, 1994.

CORREAA, Roberto Lobato. Esquemas geo(gráficos). Texto Nepec, Rio de Janeiro, n. 4, 2010. Disponível em: https://sites.google.com/site/robertolobatocorrea/publicacoes >. Acesso em novembro de 2015.

CORREAA, Roberto Lobato. Identificação dos centros de gestão do território no Brasil. Revista Brasileira de Geografia, Rio de Janeiro, a. 57, n. 1, 1995.

CORRÊA, Roberto Lobato. Interações espaciais. In: CASTRO, Iná Elias de; GOMES, Paulo César da Costa; CORRÊA, Roberto 
FRESCA, T.M. Londrina como centro de gestão do $t$ território: uma ...

Lobato (Org.). Explorações geográficas. 3 ed. Rio de Janeiro: Bertrand Brasil, 1997. p. 279-318.

CORRÊA, Roberto Lobato. Contribuição ao estudo do papel dirigente das metrópoles brasileiro. Revista Brasileira de Geografia, Rio de Janeiro, v. 30, n. 2, 1968.

CORRÊA, Roberto Lobato. Corporação e organização espacial: um estudo de caso. Revista Brasileira de Geografia, Rio de Janeiro, v. 53, n. 3, 1991a.

CORRÊA, Roberto Lobato. Corporação e espaço: uma nota. Revista Brasileira de Geografia, Rio de Janeiro, v. 53, n. 1, 1991 b.

CORRÊA, Roberto Lobato. Corporação, práticas espaciais e gestão do território. Revista Brasileira de Geografia, Rio de Janeiro, v. 54, n. 3, 1992.

CORRÊA, Roberto Lobato. Concentração bancária e os centros de gestão do território. Revista Brasileira de Geografia, Rio de Janeiro, v. 51, n. 2, 1989.

CORRÊA, Roberto Lobato. Identificação dos centros de gestão do território. Revista Brasileira de Geografia, Rio de Janeiro, v. 57, n. $1,1995$.

DUNNING, J. ; LUNDAN, S. Multinational enterprises and the global economy. Massachusets: Edward. E. Publishing Limited, 2008.

ESPÍNDOLA, Carlos J. Mudança técnica e transformações territoriais na cadeia produtiva de carne suína na Espanha e Brasil. In: ARAUJO JR; A. M.; ESPÍNDOLA, C. J. Geografia econômica: pesquisa e ensino na ação docente. Florianópolis: Edições do Bosque/CFH/UFSC, 2015. 
FRESCA, T.M. Londrina como centro de gestão do $t$ território: uma ...

FIEP. Balança comercial: exportações e importações: janeiro $2014 . \quad$ Disponível

$<$ http://www.fiepr.org.br/cinpr/servicoscin/inteligenciacomercial/uploadAddress/Balanca_01_2014[60958].pdf $>$. Acesso em novembro de 2015.

FRESCA, T. M.; OLIVEIRA, E. L. Sessenta anos de verticalização em Londrina. Revista da Anpege, v. 11, n. 16, p. 85-121, 2015.

GRUPO MUFFATO. Grupo. Disponível em: $<$ http://www.supermuffato.com.br/Institucional/pt-br/grupomuffato $>$. Acesso em setembro de 2015.

IBGE. Cadastro central de empresas: 2013. IBGE: Rio de Janeiro, 2015. Disponível em: http://biblioteca.ibge.gov.br/bibliotecacatalogo? view $=$ detalhes\&id=294246> . Acesso em janeiro de 2016.

IBGE. Produto Interno Bruto dos Municípios: 2010-2013. Disponível em:

$<$ http://biblioteca.ibge.gov.br/visualizacao/livros/liv95014.pdf> Acesso em: 23 dez. 2015.

IBGE. Gestão do território 2014: redes e fluxos do território. Rio de Janeiro: IBGE, 2014. Disponível em: $<$ http://www.ibge.gov.br/home/geociencias/geografia/redes_fluxos /gestao_do_territorio_2014/default.shtm?c=11>. Acesso em: mar. 2015.

IPARDES. Valor adicionado bruto, participação e taxa de crescimento, segundo as atividades econômicas no Paraná: 20022012.

Disponível em: $<$ http://www.ipardes.gov.br/pdf/indices/tab_pib_03.pdf $>$ Acesso em out. 2015. 
FRESCA, T.M. Londrina como centro de gestão do t território: uma ...

MAGNANINI, Ruth L. da C; LIMA, Olga M. B. Uma medida da função de direção das cidades brasileiras. Boletim Carioca de Geografia, Rio de Janeiro, v. 22, 1971.

MCGRAW, T. K. (Org.). Alfred Chandler: ensaios para uma teoria histórica da grande empresa. Rio de Janeiro: Editora FGV, 1998.

MINTZBERG et. al. O processo da estratégia: conceito, contextos e casos selecionados. Porto Alegre: Artmed, 2007.

NASCIMENTO, C. F. A verticalização de Londrina - PR: financeirização e mercado imobiliário entre 2000-2013. 2015. Dissertação (Mestrado em Geografia) - UEL, Londrina.

O EMPREITEIRO. Ranking das 500 grandes da construção. Disponível em:

http://www.revistaoempreiteiro.com.br/Conteudo/19/ranking-daengenharia-brasileira.aspx $>$. Acesso em dezembro de 2015.

OLIVEIRA, Lúcia B. de; ÁVILA, Marcos G. Descentralização em unidades de negócio: o caso de uma empresa do setor financeiro. Revista de Administração Contemporânea, Curitiba, v. 3, n. 1, 1999, p. 127-146.

PASSOS, V. R. de L. A verticalização de Londrina: 1970/2000: a ação dos promotores imobiliários. 2007. Dissertação (Mestrado em Geografia)-UEL, Londrina-PR.

PIRES DO RIO, G. A. Estrutura organizacional e reestruturação produtiva: uma contribuição para a geografia das corporações. Revista Território, Rio de Janeiro, a. 3, v. 5, jul/dez. 1998.

PIRES DO RIO, G. A. Organizações empresariais, trajetórias espaciais e racionalidade: espaço e tempo de uma empresa de celulose. Revista Território, Rio de Janeiro, a. 5, v. 8, jan/jun. 2000 . 
FRESCA, T.M. Londrina como centro de gestão do t território: uma ...

PORTAL DO COOPERATIVISMO FINANCEIRO. Dados consolidados dos sistemas cooperativos. Disponível em: < http:/cooperativismodecredito.coop.br/cenario-mundial/cenariobrasileiro/dados-consolidados-dos-sistemas-cooperativos/ >. Acesso em dez. 2015.

PRED, Alan. Sistemas de cidades em economias adiantadas: crescimento passado, processos presentes e opções de desenvolvimento futuro. Rio de Janeiro: Zahar Editores, 1979.

RANGEL, I. Obras reunidas. Rio de Janeiro: Contraponto, 2005, 2. v.

ROZENBLAT, Céline. The organization of multinational firms in the European urban system. Flux, n. 17, 1994. pp. 5-17. Disponível em: $\quad<$ http://www.persee.fr/doc/flux_11542721_1994_num_10_17_991>. Acesso em 06 de setembro 2015.

SAAB, Thiago B. As micro e pequenas empresas e a dinâmica industrial londrinense: 1992-2011. 2014. Dissertação (Mestrado em Geografia) - UEL, Londrina.

SANTOS, M. A natureza do espaço: técnica, tempo, razão e emoção. São Paulo, HUCITEC, 1996.

SANTOS, Milton. Espaço e sociedade: ensaios. $2^{\mathrm{a}}$ ed. Petrópolis: Vozes, 1982.

SANTOS, Milton. Espaço e método. São Paulo: Nobel, 1985.

TOLEDO, Marcio Roberto; KAHIL, Samira P. A constituição de novas regiões por empresas multilocalizadas: o caso da Nestlé de Araras-SP. Geosul, Florianópolis, v. 19, n. 38, p 59-76, 2004. 
FRESCA, T.M. Londrina como centro de gestão do $t$ território: uma ...

UNIPRIME COOPERATIVA DE CRÉDITO. Linha do tempo. Disponível em: < https://www.uniprimebr.com.br/historia.php? modo=popup $>$. Acesso em dezembro de 2015.

VALOR ECONÔMICO. Valor 1000: 2015. Disponível em: < http://www.valor.com.br/valor1000/2015/ranking1000maiores>. Acesso em setembro de 2015.

Recebido em Aceito em 